\title{
Article \\ CFD-Based In-Depth Investigation of the Effects of the Shape and Layout of a Vortex Generator on the Aerodynamic Performance of a Multi-MW Wind Turbine
}

\author{
Hyeon-Gi Moon ${ }^{1}$, Sunho Park ${ }^{2}$, Kwangtae $\mathrm{Ha}^{3, *}$ and Jae-Ho Jeong ${ }^{1, *}$ \\ 1 Mechanical Engineering, Gachon University, 1342, Seongnam-daero, Sujeong-gu, Seongnam-si 13306, Korea; \\ 91ngk@gachon.ac.kr \\ 2 Unison Wind Power R\&D Centre, 26-41, Gaeongbuk-ro, Yuseong-gu, Daejeon 34113, Korea; shp@unison.co.kr \\ 3 Department of Floating Wind Power, Ulsan University, 93, Daehak-ro, Nam-gu, Ulsan 44610, Korea \\ * Correspondence: kwangtaeha@ulsan.ac.kr (K.H.); jaeho.jeong@gachon.ac.kr (J.-H.J.); \\ Tel.: +82-(031)-750-5654 (J.-H.J.)
}

check for

updates

Citation: Moon, H.-G.; Park, S.; Ha, K.; Jeong, J.-H. CFD-Based In-Depth Investigation of the Effects of the Shape and Layout of a Vortex Generator on the Aerodynamic Performance of a Multi-MW Wind Turbine. Appl. Sci. 2021, 11, 10764. https://doi.org/10.3390/app112210764

Academic Editor: Daniel

Villanueva Torres

Received: 1 October 2021

Accepted: 8 November 2021

Published: 15 November 2021

Publisher's Note: MDPI stays neutral with regard to jurisdictional claims in published maps and institutional affiliations.

Copyright: (c) 2021 by the authors. Licensee MDPI, Basel, Switzerland. This article is an open access article distributed under the terms and conditions of the Creative Commons Attribution (CC BY) license (https:// creativecommons.org/licenses/by/ $4.0 /)$.

\begin{abstract}
Thick airfoils are conventionally adopted in the blade root region of a wind turbine to ensure structural safety under extreme conditions, despite the resulting power loss. To prevent this loss, a passive flow control device known as a vortex generator (VG) is installed at the starting point of the stall to control the flow field near the wall of the suction surface. In this study, we used computational fluid dynamics (CFD) to investigate the aerodynamic characteristics induced as a result of the shape and layout of the VG on a multi-MW wind turbine blade. The separated and vortical flow behavior on the suction surface of the wind turbine blade equipped with VGs was captured by the Reynolds-averaged Navier-Stokes (RANS) steady-flow simulation. The parametric sensitivity study of the VG shape parameters such as the chord-wise length, height, and interval of the fair of VGs was conducted using thick DU airfoil on the blade inboard area. Based on these results, the response surface method (RSM) was used to investigate the influence of the design parameters of the VG. Based on the CFD results, the VG design parameters were selected by considering the lift coefficient and vorticity above the trailing edge. The maximum vorticity from the trailing edge of the selected VG and the lift coefficient were $55.7 \%$ and $0.42 \%$ higher, respectively, than the average. The selected VG design and layout were adopted for a multi-MW wind turbine and reduced stall occurrence in the blade root area, as predicted by the simulation results. The VG improved the aerodynamic performance of the multi-MW wind turbine by $2.8 \%$ at the rated wind speed.
\end{abstract}

Keywords: vortex generator; computational fluid dynamics; wind turbine blade; stall

\section{Introduction}

Interest in improving the performance of wind turbines by optimizing the methods used for blade design and flow control devices has grown in the last few decades. In particular, several research efforts have focused on refining these methods to increase the efficiency of wind turbines [1-5]. Wind turbine manufacturers have attempted to increase the blade length not only to improve the annual energy production (AEP), but also to lower the cost of energy [6]. Traditionally, the wind industry has performed aerodynamic blade design and performance analysis based on Blade Element Momentum Theory (BEMT). Aerodynamic blade design methods for wind turbines were reviewed previously [7-10]. The design method based on BEMT applies various types of loss-correction models [11-13] to the tip and hub of the blade, where the three-dimensional flow field is dominant. However, the problem of aerodynamic reliability with high accuracy persists in the various loss-correction models based on BEMT, owing to the enlargement of the blade length and the taper of the blade tip. To overcome the reliability problem, a 3D steady-flow simulation using CFD was performed after preliminarily performing a blade design based on BEMT. 
The aerodynamic performance and load of the blade, and the complex 3D viscous flow field around the blade tip and hub were evaluated using the previous simulation results $[14,15]$.

In this study, the use of a vortex generator (VG) as a passive performance-enhancing device for a large wind turbine was studied. A VG is a passive flow control device in the form of a small vane and is mainly used to delay the stall occurrence of an airplane blade [16-18] or even to improve the heat transfer performance by forming longitudinal vortices [19]. In the wind energy industry, the VG has been studied to improve the aerodynamic performance of wind turbines installed on flat terrain, as well as to extend their lifespan through the wind-kinetic energy conversion of wind turbines installed on complex terrain [20]. The effectiveness of the VG has been proven through academiaindustry joint research, and it has been installed and operated in thousands of wind turbines since 2013 [21]. VGs are installed toward the root and suction surface of the blade of a wind turbine to mitigate airflow separation. Many CFD analyses and wind tunnel tests have been carried out to assess the feasibility of VG adoption with wind turbine blades. However, few CFD studies focused on full-scale wind turbines equipped with Gurney flap VGs other than airfoil base simulation and wind tunnel testing or CFD using virtual porous models [22-27]. There was a CFD analysis study of the VG-mounted wind turbine blade by RANS, SST k-omega equation, but the blade length was as short as $35 \mathrm{~m}$, and a cuboid VG was investigated for the convenience of lattice formation [28]. Although there have been studies that calculate power increase via BEM using the lift and drag coefficient, calculations using BEM are less accurate than RANS CFD analysis results [29]. The aerodynamic characteristics of multi-MW horizontal-axis wind turbine blades have been analyzed using the commercial CFD software ANSYS CFX [30]. The results of the CFD analysis were validated with GH-Bladed design data [31]. These researchers optimized the shape and layout of the VG to maximize the performance of the wind turbine in terms of power generation.

\section{Materials and Methods}

Considering the aerodynamics and structural aspects of the blade, the airfoils shown in Figure 1 are extended in the span direction as shown in Figure 2. Figure 3 schematically shows the main parameters and layout of the VG. The distance between the VG pairs $(\lambda)$ and the angle of attack $(\alpha)$ of the VG were specified as $6^{\circ}$ and $11^{\circ}$ for efficiency. The recommended $\lambda / \mathrm{h}$ investigated through a flat-plane CFD analysis study is 5 [32]. The VGs are installed on the suction surface and at the root of the blade to enhance the aerodynamic performance. Table 1 presents the wind turbine specification and Table 2 the shape parameters of the VG normalized by the chord length.

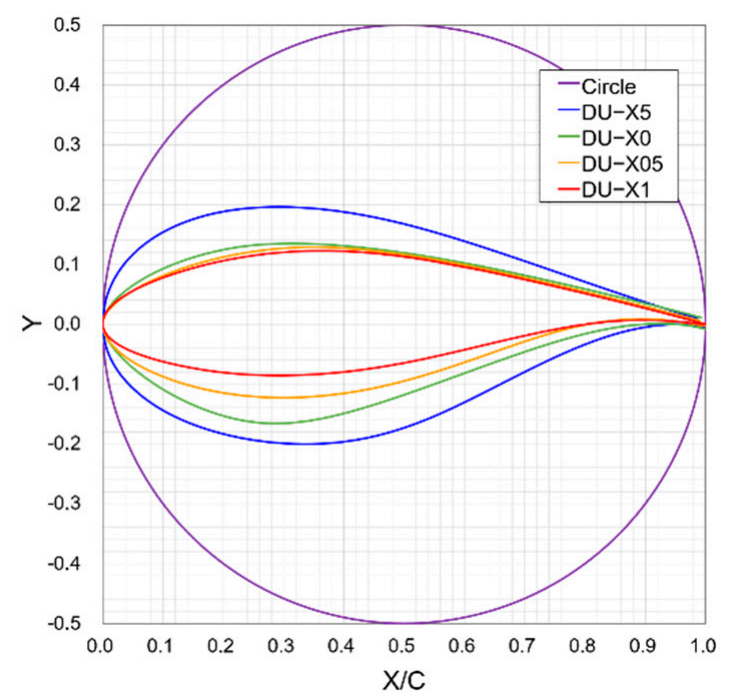

Figure 1. Airfoil series. 


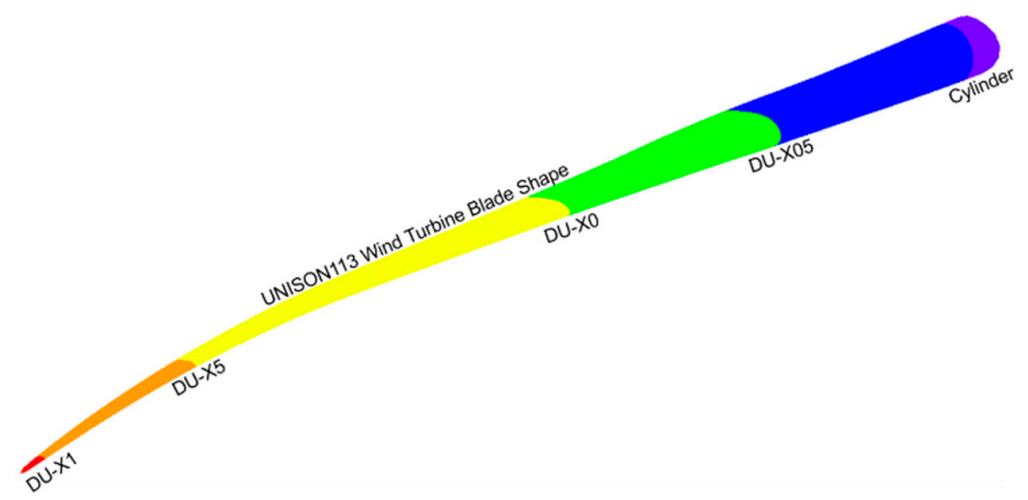

Figure 2. Three-dimensional form of the blade of the wind turbine.

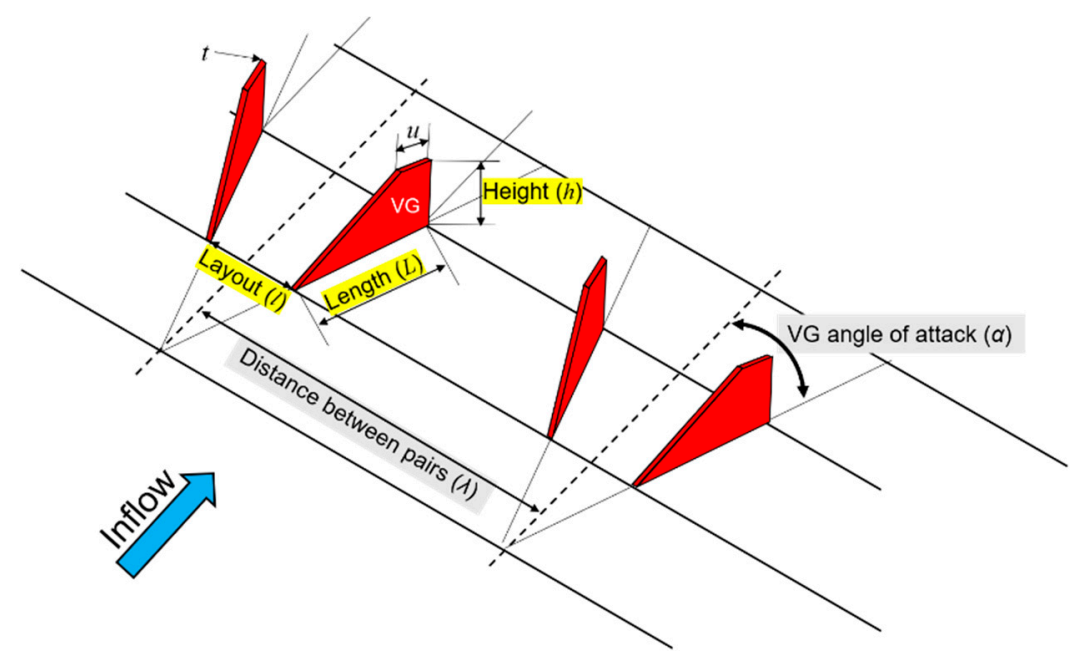

Figure 3. Schematic diagram of VG and the design variables.

Table 1. Wind turbine specification.

\begin{tabular}{cc}
\hline Category & Value \\
\hline Simulation region & Volume \\
\hline Number of blades & 3 \\
\hline Rotor diameter & $113 \mathrm{~m}$ \\
\hline Rotational speed & variable \\
\hline Rated wind speed & $10 \mathrm{~m} / \mathrm{s}$ \\
\hline Rated wind power & $2.3 \mathrm{MW}$ \\
\hline Rotational direction & clockwise (viewed from upwind) \\
\hline Blade profile & DU airfoils \\
\hline Target wind class & Class II \\
\hline
\end{tabular}

Table 2. VG specification normalized by the chord length.

\begin{tabular}{cc}
\hline Category & Value \\
\hline Number of VGs per blade & 45 \\
\hline Mounting position & $\begin{array}{c}10 \sim 30 \% \text { of blade length from blade root, } 20 \% \text { of } \\
\text { chord length from leading edge }\end{array}$ \\
\hline Layout & $1.5 \%$ \\
\hline Length & $1.5 \%$ \\
\hline Height & $1 \%$ \\
\hline Angle to the direction of the chord & $11^{\circ}$ \\
\hline
\end{tabular}




\subsection{Numerical Analysis Methodology}

Three major numerical analysis techniques, namely, direct numerical simulation (DNS) [33], large eddy simulation (LES) [34], and RANS simulation, can be used to analyze turbulent flow fields. To analyze the general vortex behavior precisely in a turbulent flow field containing vortices of various scales, the calculation grid size must be smaller than the minimum space scale of the vortex structure and the time interval should be less than the minimum time scale of the vortex variation. LES uses the spatially averaged Navier-Stokes equations, which directly calculate vortices greater than the grid scale and indirectly refer to the subgrid-scale model for vortices smaller than the grid scale. DNS and LES require extensive resources for their calculations, making them unfeasible in practical engineering applications. In comparison, RANS uses the time-based ensemble-averaged Navier-Stokes equations and models all of the effects caused by turbulence. Although RANS yields a lower resolution analysis than DNS or LES, it is widely used in engineering applications because it does not require high-resolution calculation grids. RANS uses the following equations:

$$
\begin{gathered}
\frac{\partial \rho}{\partial t}+\frac{\partial}{\partial x_{j}}\left(\rho U_{j}\right)=0 \\
\frac{\partial\left(\rho U_{i}\right)}{\partial t}+\frac{\partial}{\partial x_{j}}\left(\rho U_{i} U_{j}\right)=-\frac{\partial \rho}{\partial x_{i}}+\frac{\partial}{\partial x_{j}}\left(\tau_{i j}-\rho \overline{u_{i} u_{j}}\right)+S_{M}
\end{gathered}
$$

Turbulence models that are widely used for RANS numerical analysis in engineering include $k-\varepsilon, k-\omega$, and SST. The $k-\varepsilon$ turbulence model [35] precisely analyzes the turbulence behavior in free-stream regions with small pressure gradients; however, it inaccurately estimates the boundary layer separation in viscous sub-layer regions. Although the $k-\omega$ turbulence model, which was developed by Wilcox [36], accurately analyzes the separation caused by adverse pressure gradients, it is sensitive to the free-stream region. Menter [37] combined the advantages of the $k-\varepsilon$ and $k-\omega$ models and proposed the SST turbulence model. Simulation of the wind turbine flow generally involves the use of CFD to analyze the performance of the cross-sectional airfoil of the blade, and the numerical analysis and experimental results are often in agreement [38,39]. The complete formulation of the SST model is given by:

$$
\begin{array}{r}
\frac{\partial(\rho k)}{\partial t}+\frac{\partial\left(\rho U_{i} k\right)}{\partial x_{i}}=\widetilde{P}_{k}-\beta^{*} \rho k \omega+\frac{\partial}{\partial x_{i}}\left[\left(\mu+\sigma_{k} \mu_{t}\right) \frac{\partial k}{\partial x_{i}}\right] \\
\frac{\partial(\rho \omega)}{\partial t}+\frac{\partial\left(\rho U_{i} \omega\right)}{\partial x_{i}}=\alpha \rho S^{2}-\beta \rho \omega^{2}+\frac{\partial}{\partial x_{i}}\left[\left(\mu+\sigma_{\omega} \mu_{t}\right) \frac{\partial \omega}{\partial x_{i}}\right]+2\left(1-F_{1}\right) \rho \sigma_{w 2} \frac{1}{\omega} \frac{\partial k}{\partial x_{i}} \frac{\partial \omega}{\partial x_{i}}
\end{array}
$$

The blending function $F_{1}$ is defined by:

$$
F_{1}=\tanh \left\{\left\{\min \left[\max \left(\frac{\sqrt{k}}{\beta^{*} \omega y}, \frac{500 v}{y^{2} \omega}\right), \frac{4 \rho \sigma_{\omega^{2}} k}{C D_{k \omega} y^{2}}\right]\right\}^{4}\right\}
$$

where $C D_{k \omega}=\max \left(2 \rho \sigma_{\omega 2} \frac{1}{\omega} \frac{\partial k}{\partial x_{i}} \frac{\partial \omega}{\partial x_{i}}, 10^{-10}\right)$ and $y$ is the distance to the nearest wall. The turbulent eddy viscosity is defined as follows:

$$
v_{t}=\frac{\alpha_{1} k}{\max \left(\alpha_{1} \omega, S F_{2}\right)}
$$

The second blending function $F_{2}$ is defined by:

$$
F_{2}=\tanh \left[\left[\max \left(\frac{2 \sqrt{k}}{\beta^{*} \omega y}, \frac{500 v}{y^{2} \omega}\right)\right]^{2}\right]
$$


A production limiter is used in the SST model to prevent the build-up of turbulence in stagnation regions:

$$
P_{k}=\mu_{t} \frac{\partial U_{i}}{\partial x_{j}}\left(\frac{\partial U_{i}}{\partial x_{j}}+\frac{\partial U_{j}}{\partial x_{i}}\right) \rightarrow \widetilde{P}_{k}=\min \left(P_{k}, 10 \cdot \beta^{*} \rho k \omega\right)
$$

\subsection{Implementation of Vortex Generators on a Wind Turbine Blade}

To accurately calculate $\omega$ (specific dissipation) in the viscous sub-layer region using RANS simulation with the SST turbulence model, the minimum grid size must satisfy $y+<1$ in the viscous sub-layer simulation [40]. Figure 4 shows the blade calculation area. In the calculation domain, a spatial resolution of 7 times the rotor radius in the inflow direction, 10 times the wake direction, and 10 times the radial direction was configured. A no-slip condition was applied to the blade surface equipped with the VG, and a freestream condition was applied to the inlet. The flow field of the wind turbine blade was simulated by applying a $120^{\circ}$ periodic boundary condition in the direction of rotation. The interface between the rotating and fixed parts was analyzed by applying the frozen interface condition.

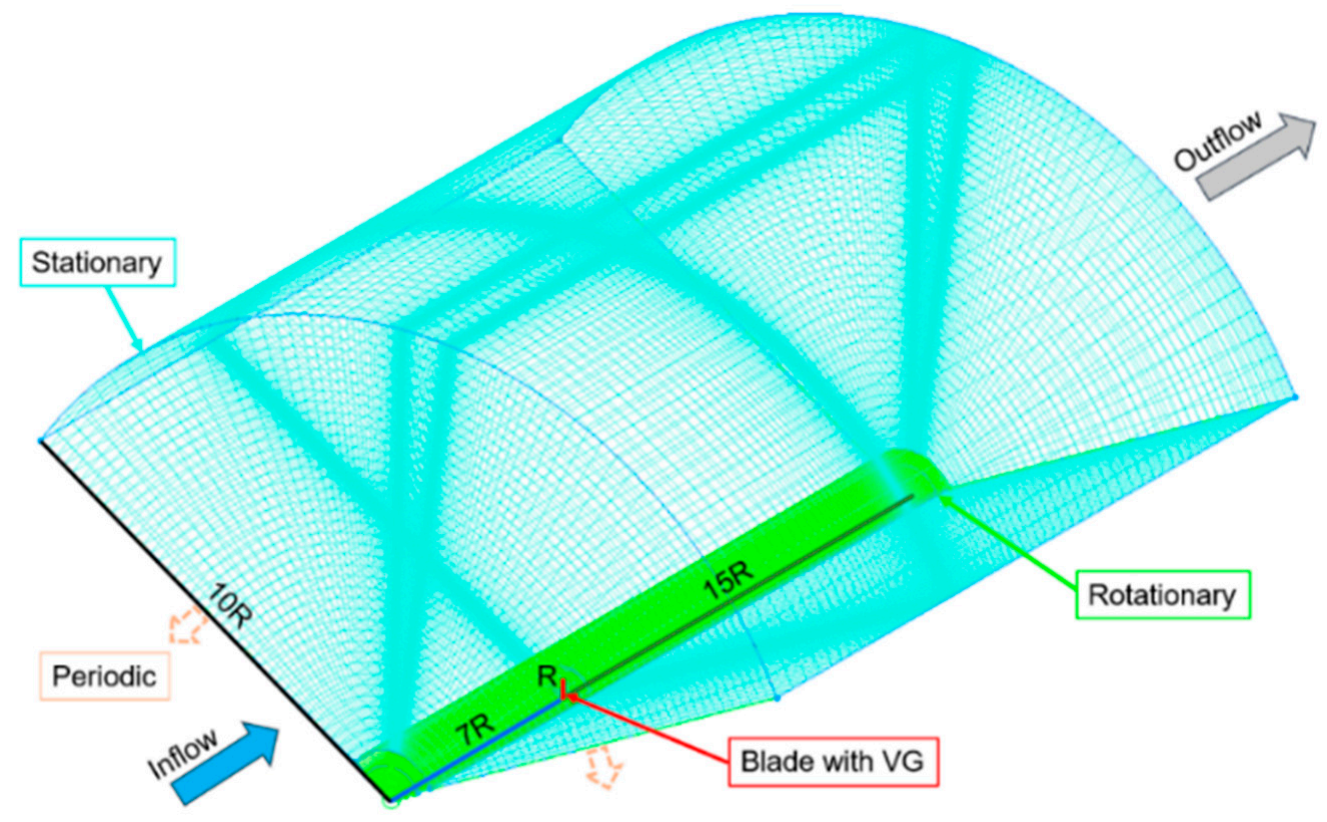

Figure 4. Grid for the simulation of a VG mounted blade.

\section{Results and Discussion}

\subsection{Validation of CFD Model}

The results of the CFD analysis of the wind turbine blade without a VG were compared with experimental BEMT data. The BEMT-based analysis was carried out using GH Bladed, which is commercial code used for wind turbine design. Figures 4 and 5 shows the computational grid system of the blades in the simulation, and Table 3 provides the number of elements in the computational grid system used for the simulation. Figure 6 and Table 4 present the results of the CFD analysis of the blade and the GH Bladed design values. These results are confirmed to be consistent within a margin of error of $0.24 \%$ at a wind speed of $7.5 \mathrm{~m} / \mathrm{s}$ and $2.36 \%$ at a rated speed of $10 \mathrm{~m} / \mathrm{s}$. 


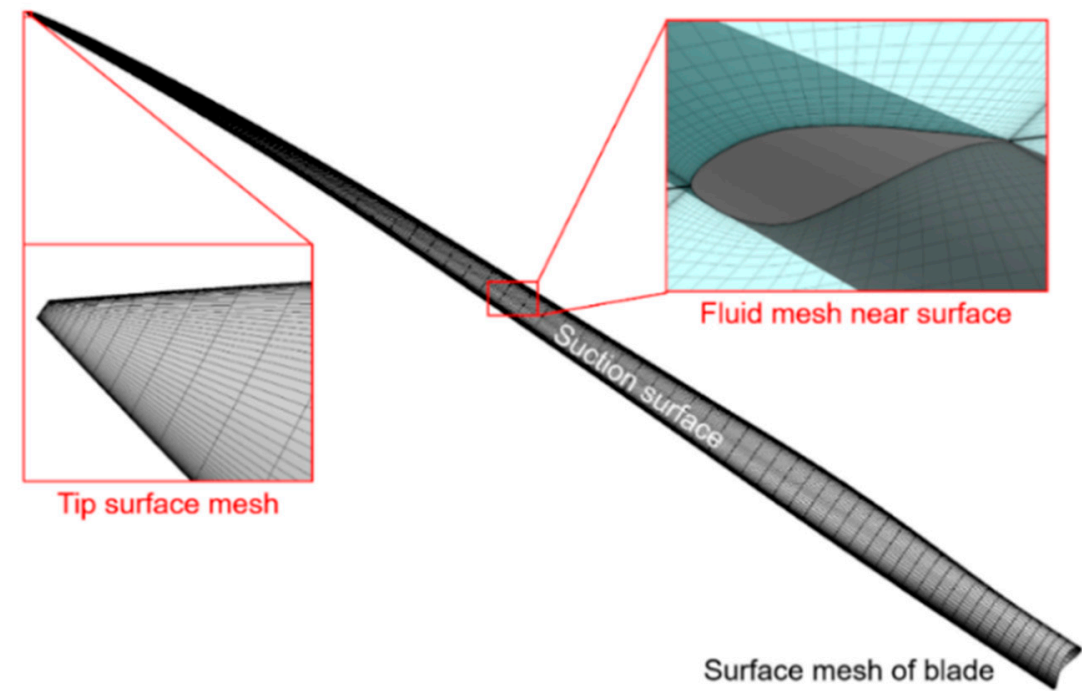

Figure 5. Surface mesh of plain blade.

Table 3. Number of elements of blade for numerical analysis.

\begin{tabular}{ccc}
\hline Simulation Area & Volume (-) & Number of Elements (EA) \\
\hline \multirow{2}{*}{ Blade } & Rotationary & $4,060,800$ \\
& Stationary & 576,000 \\
& Total & $4,636,800$ \\
\hline
\end{tabular}

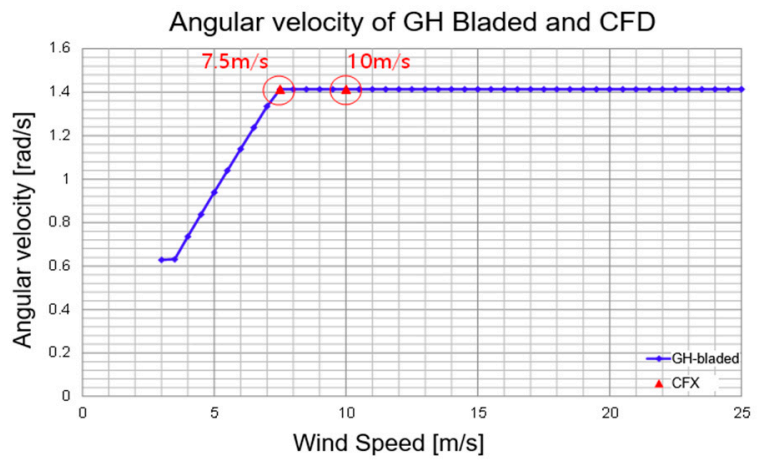

(a)

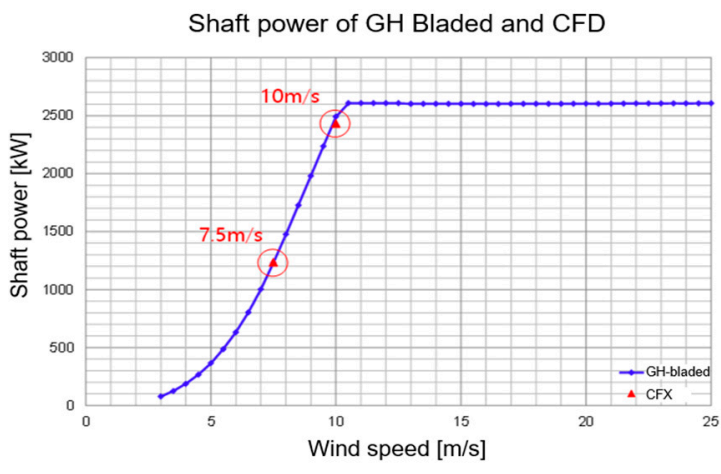

(b)

Figure 6. Comparison of the results of the angular velocity and axis output computed using GH Bladed design data and CFD. (a) Angular velocity. (b) Shaft power.

Table 4. BEMT design data and CFD results.

\begin{tabular}{cccccc}
\hline Case & $\begin{array}{c}\text { Wind Speed } \\
(\mathbf{m} / \mathbf{s})\end{array}$ & $\begin{array}{c}\text { Angular Velocity } \\
(\mathbf{r a d} / \mathbf{s})\end{array}$ & $\begin{array}{c}\text { GH-Bladed } \\
\text { Power }(\mathbf{k W})\end{array}$ & $\begin{array}{c}\text { CFD Power } \\
\mathbf{( k W )}\end{array}$ & Note \\
\hline 1 & 7.5 & 1.41372 & 1232.18 & 1235.7 & $0.24 \%$ \\
\hline 2 & 10.0 & 1.41372 & 2491.71 & 2432.4 & $2.36 \%$ \\
\hline
\end{tabular}

\subsection{Flow Behavior on the Wind Turbine Blade}

The simulation was performed by specifying many grids in the wake direction of the blade tip to accurately simulate the tip vortex, and these results are shown in Figure 7. Vortex core 1 is generated in the boundary layer of the suction surface, and vortex core 2 is combined with vortex core 1 in the boundary layer of the pressure surface. Vortex core 3 is a boundary layer generated at the blade trailing edge and is swept into the tip 
vortex structure. As shown in Figure 8, large-scale flow separation occurred at a distance of approximately $20 \%$ of the chord length from the leading edge. The airflow characteristics on the suction surface of the blade were affected by the thickness ratio of the airfoil and the angle of attack depending on the wind speed. The flow-separated low-energy air was confirmed to flow secondarily in the tip direction along the suction surface owing to forces such as the centrifugal force, Coriolis force, and pressure difference in the radial direction of the rotor.

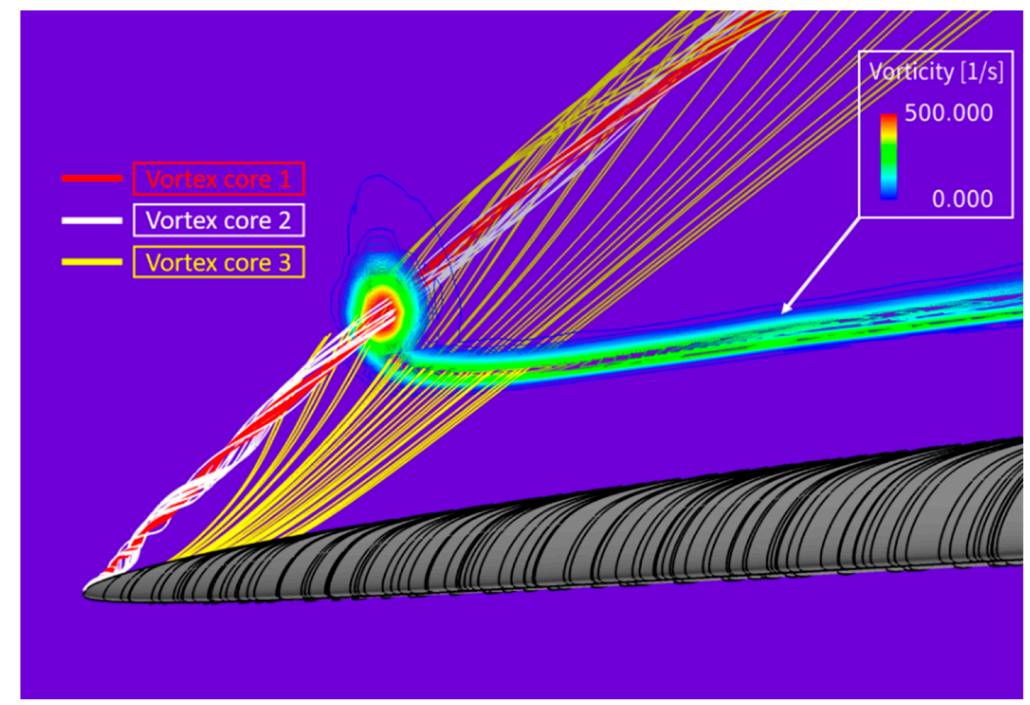

Figure 7. Vortex flow structure near the tip.

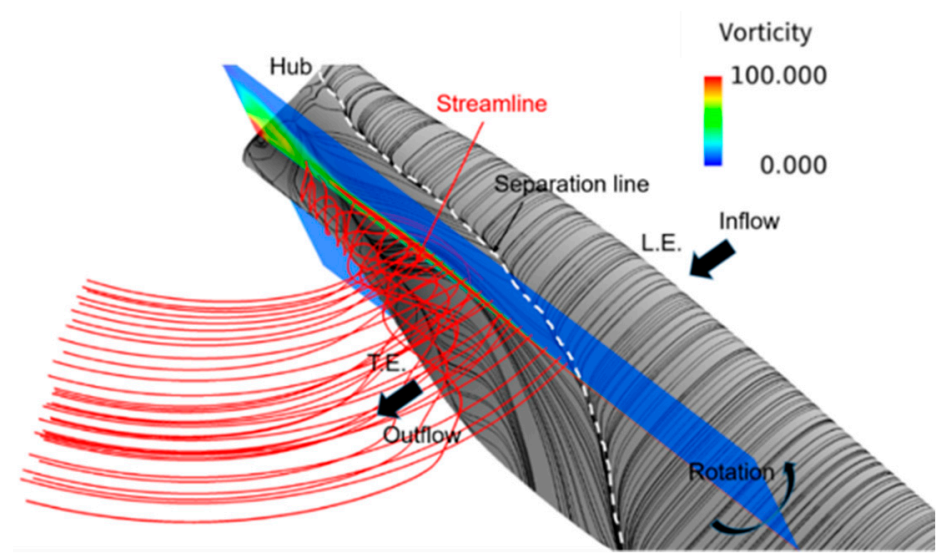

Figure 8. Separated flow structure near the root.

\subsection{Aerodynamic Characteristics of DU Airfoil with VG}

Based on the results of the CFD analysis, the cross-sectional DU airfoil in the region where flow separation occurs predominantly was selected as the test airfoil for VG application analysis. Figure 9 shows the surface grid of the VG-equipped airfoil used for simulation, and Table 5 contains the number of grids that were used.

The chordwise velocity contours of the airfoil with and without the VG are shown in Figure 10a,b. The results of the CFD analysis confirm that, in the case of the airfoil without the VG, the fluid did not accelerate along the suction surface and flow separation occurred; however, in the case of the airfoil with the VG, the fluid accelerated along the suction surface and flow separation did not occur. When flow separation occurs on the suction side, a low-pressure region is formed in the wake, which lowers the lift coefficient and increases the drag coefficient. As shown in Figure 11a,b, when the VG is attached, the airfoil experienced a high lift force at an angle of attack of $5.9^{\circ}$ or higher and a low drag force at an angle of attack of $14.8^{\circ}$ or higher. 


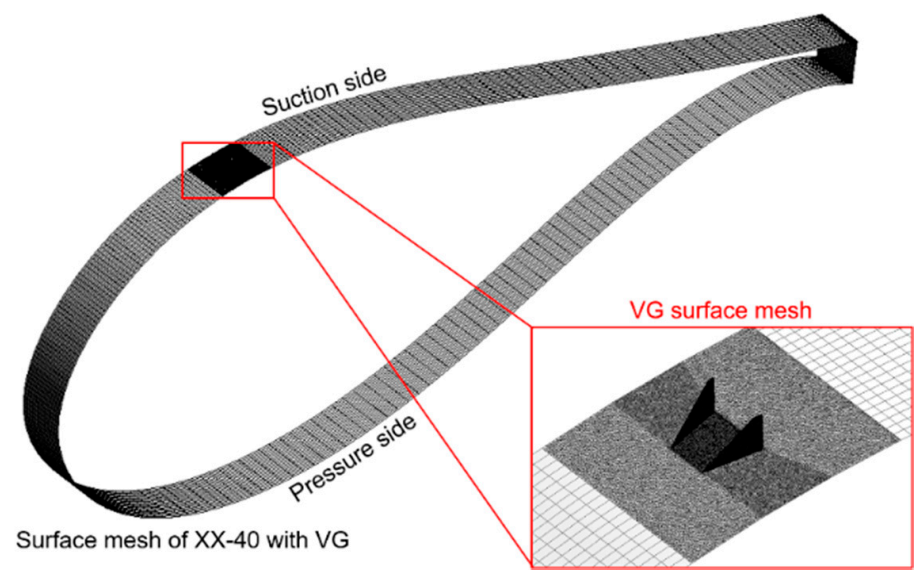

Figure 9. Surface mesh of VG-mounted airfoil extruded in the span direction.

Table 5. Number of elements for the numerical analysis of the VG-mounted airfoil.

\begin{tabular}{ccc}
\hline Simulation Area & Volume (-) & Number of Elements (EA) \\
\hline \multirow{2}{*}{ VG airfoil } & VG & $1,932,483$ \\
& Region surrounding the VG & $3,924,000$ \\
& Total & $5,856,483$ \\
\hline
\end{tabular}

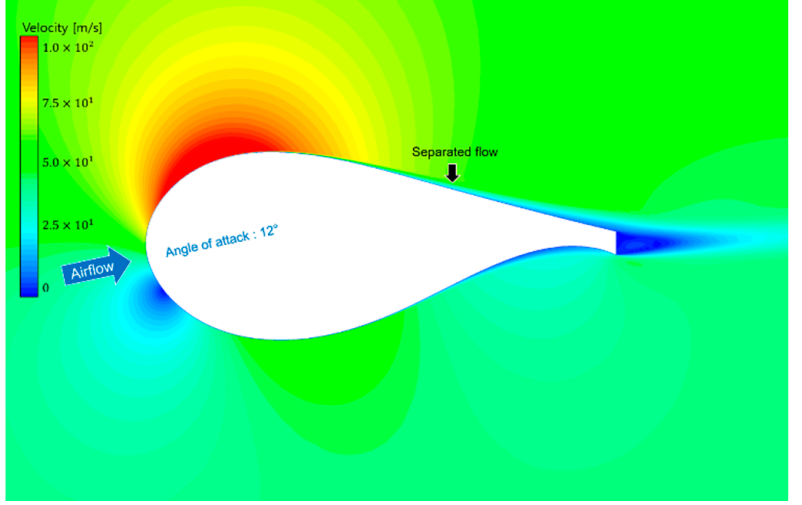

(a)

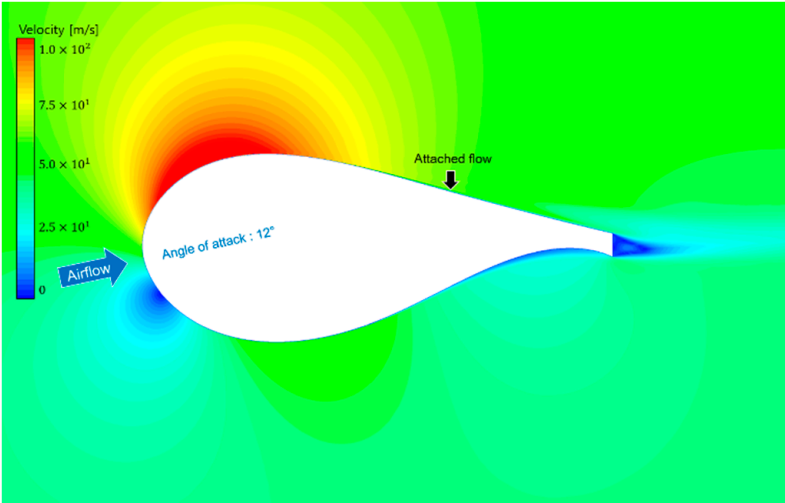

(b)

Figure 10. Cross-sectional velocity contour of the blade: (a) without VG; (b) with VG.

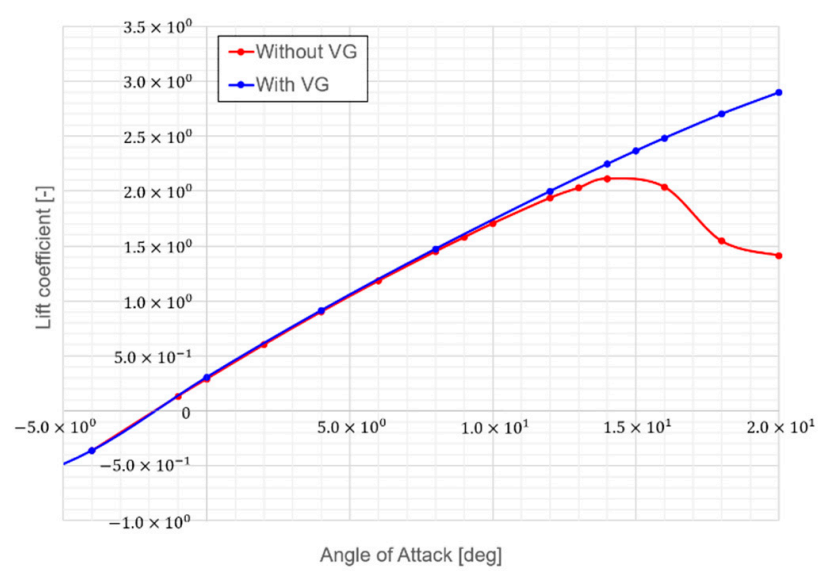

(a)

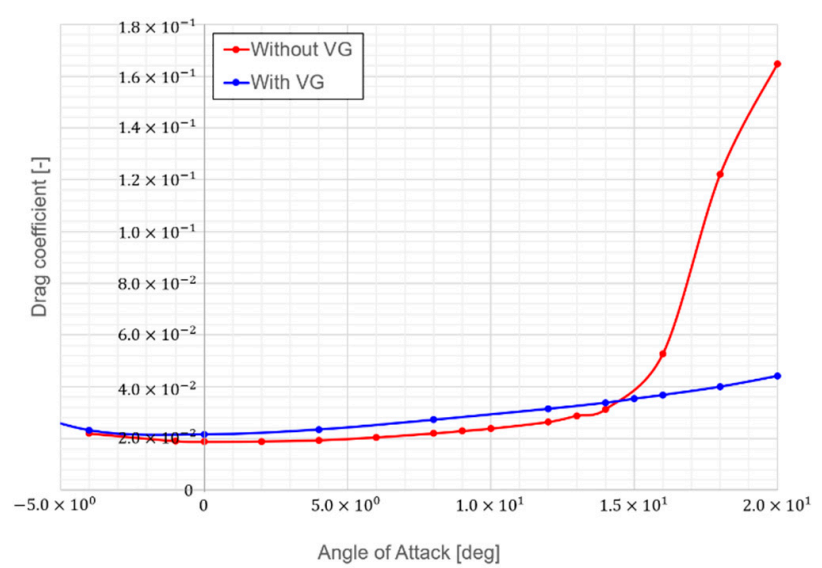

(b)

Figure 11. Lift and drag coefficient vs. angle of attack: (a) lift coefficient; (b) drag coefficient. 


\subsection{Investigation of the Influence of VG Design Parameters}

The design variables and layout of the VG are shown in Figure 3, where the thickness $t$ is fixed at 0.05 and the length of the upper section $u$ is fixed at 0.2. A total of 27 CFD analyses were performed, and the variables used in each of these cases are listed in Table 6. In the analyses, the Reynolds number and angle of attack were set to $3.0 \times 10^{6}$ and $12^{\circ}$, respectively. The results of these case studies are presented in Table 7. Figures 12 and 13 show the vorticity contours for cases 1,2,3,5,8,11, and 20 at locations $50 \%$ and $100 \%$ of the chord length from the leading edge, respectively. In Figure 13, the vorticity contour at the trailing edge can be compared when each parameter is changed based on case 2 .

The response surface methodology (RSM) used a LOWESS (Locally Weighted Scatterplot Smoother) second equation to find combinations that could represent the best VG effect using the three independent design parameters, layout $(L)$, length $(l)$, and height $(h)$, as shown in Figure 3 [41]. Four objective variables, $C_{L}, C_{D}$, and the maximum vorticity at the positions $50 \%$ and $100 \%$ from the leading edge to the trailing edge, were investigated. The correlation between the $C_{L}$ values is shown for these cases in Figure 14 as $3 \mathrm{D}$ surface plots. In this figure, the value calculated for $C_{L}$ tends to be higher as the length $(L)$ is closer to the median value and the height $(h)$ and layout $(l)$ are lower. The correlation between the maximum vorticity values of the trailing edge is also shown in terms of the three parameters in Figure 15. Unlike $C_{L}$, the calculated value of the maximum vorticity of the trailing edge tends to be higher for $l$, lower for $L$, and that of $h$ is closer to the median value. The VG design parameter selection criteria, more weight assigned to the maximum vorticity at the trailing edge, and the parameters were selected as shown in Figure 3 in consideration of manufacturability.

Table 6. Values of the analyzed VG design parameters.

\begin{tabular}{|c|c|c|c|}
\hline Case & Layout ( $l$ ) & Length $(L)$ & Height $(h)$ \\
\hline 01 & $1.5 \%$ & $1.5 \%$ & $0.75 \%$ \\
\hline 02 & $1.5 \%$ & $1.5 \%$ & $1 \%$ \\
\hline 03 & $1.5 \%$ & $1.5 \%$ & $1.25 \%$ \\
\hline 04 & $1.5 \%$ & $1.75 \%$ & $0.75 \%$ \\
\hline 05 & $1.5 \%$ & $1.75 \%$ & $1 \%$ \\
\hline 06 & $1.5 \%$ & $1.75 \%$ & $1.25 \%$ \\
\hline 07 & $1.5 \%$ & $2 \%$ & $0.75 \%$ \\
\hline 08 & $1.5 \%$ & $2 \%$ & $1 \%$ \\
\hline 09 & $1.5 \%$ & $2 \%$ & $1.25 \%$ \\
\hline 10 & $2 \%$ & $1.5 \%$ & $0.75 \%$ \\
\hline 11 & $2 \%$ & $1.5 \%$ & $1 \%$ \\
\hline 12 & $2 \%$ & $1.5 \%$ & $1.25 \%$ \\
\hline 13 & $2 \%$ & $1.75 \%$ & $0.75 \%$ \\
\hline 14 & $2 \%$ & $1.75 \%$ & $1 \%$ \\
\hline 15 & $2 \%$ & $1.75 \%$ & $1.25 \%$ \\
\hline 16 & $2 \%$ & $2 \%$ & $0.75 \%$ \\
\hline 17 & $2 \%$ & $2 \%$ & $1 \%$ \\
\hline 18 & $2 \%$ & $2 \%$ & $1.25 \%$ \\
\hline 19 & $2.5 \%$ & $1.5 \%$ & $0.75 \%$ \\
\hline 20 & $2.5 \%$ & $1.5 \%$ & $1 \%$ \\
\hline 21 & $2.5 \%$ & $1.5 \%$ & $1.25 \%$ \\
\hline 22 & $2.5 \%$ & $1.75 \%$ & $0.75 \%$ \\
\hline 23 & $2.5 \%$ & $1.75 \%$ & $1 \%$ \\
\hline 24 & $2.5 \%$ & $1.75 \%$ & $1.25 \%$ \\
\hline 25 & $2.5 \%$ & $2 \%$ & $0.75 \%$ \\
\hline 26 & $2.5 \%$ & $2 \%$ & $1 \%$ \\
\hline 27 & $2.5 \%$ & $2 \%$ & $1.25 \%$ \\
\hline
\end{tabular}


Table 7. Results of case studies to select the VG design variables.

\begin{tabular}{|c|c|c|c|c|c|c|}
\hline \multirow{2}{*}{ Case } & \multirow{2}{*}{$\mathrm{Cl}$} & \multirow{2}{*}{$\mathrm{Cd}$} & \multicolumn{4}{|c|}{ Maximum Vorticity at Position in the Direction of the Chord (1/s) } \\
\hline & & & $25 \%$ & $50 \%$ & $75 \%$ & $100 \%$ \\
\hline 01 & 2.026 & 0.0285 & 10,363 & 3078 & 3033 & 1625 \\
\hline 02 & 2.010 & 0.0302 & 10,289 & 3370 & 3054 & 1766 \\
\hline 03 & 1.974 & 0.0627 & 13,641 & 3773 & 2535 & 1200 \\
\hline 04 & 2.013 & 0.0293 & 13,554 & 3245 & 2472 & 1154 \\
\hline 05 & 1.990 & 0.0327 & 16,308 & 3712 & 2374 & 975 \\
\hline 06 & 1.978 & 0.0344 & 14,352 & 3912 & 2449 & 1128 \\
\hline 07 & 2.014 & 0.0291 & 13,926 & 3205 & 2335 & 1128 \\
\hline 08 & 1.996 & 0.0319 & 16,066 & 3698 & 2338 & 1101 \\
\hline 09 & 1.978 & 0.0348 & 15,392 & 3675 & 2233 & 1112 \\
\hline 10 & 2.113 & 0.0289 & 12,809 & 3092 & 2497 & 1205 \\
\hline 11 & 2.001 & 0.0315 & 13,846 & 3471 & 2446 & 1061 \\
\hline 12 & 1.991 & 0.0332 & 12,298 & 2876 & 1965 & 969 \\
\hline 13 & 1.993 & 0.0306 & 13,626 & 2890 & 1859 & 830 \\
\hline 14 & 2.004 & 0.0311 & 14,949 & 3463 & 2423 & 1141 \\
\hline 15 & 1.854 & 0.0220 & 12,029 & 2490 & 1392 & 674 \\
\hline 16 & 2.019 & 0.0287 & 14,391 & 3001 & 2391 & 1209 \\
\hline 17 & 2.004 & 0.0314 & 16,751 & 3452 & 2255 & 1117 \\
\hline 18 & 2.000 & 0.0309 & 16,487 & 3616 & 2237 & 1071 \\
\hline 19 & 2.019 & 0.0285 & 13,107 & 2865 & 2409 & 1147 \\
\hline 20 & 2.008 & 0.0309 & 14,943 & 3211 & 2177 & 1111 \\
\hline 21 & 2.002 & 0.0322 & 12,821 & 2622 & 1704 & 955 \\
\hline 22 & 2.021 & 0.0283 & 13,380 & 3134 & 2404 & 1235 \\
\hline 23 & 2.010 & 0.0307 & 15,369 & 3498 & 2174 & 1196 \\
\hline 24 & 1.996 & 0.0331 & 16,024 & 3433 & 2104 & 1097 \\
\hline 25 & 2.020 & 0.0282 & 13,507 & 3228 & 2336 & 1266 \\
\hline 26 & 2.009 & 0.0308 & 16,087 & 3596 & 2106 & 1195 \\
\hline 27 & 2.002 & 0.0325 & 15,635 & 2373 & 1614 & 966 \\
\hline
\end{tabular}

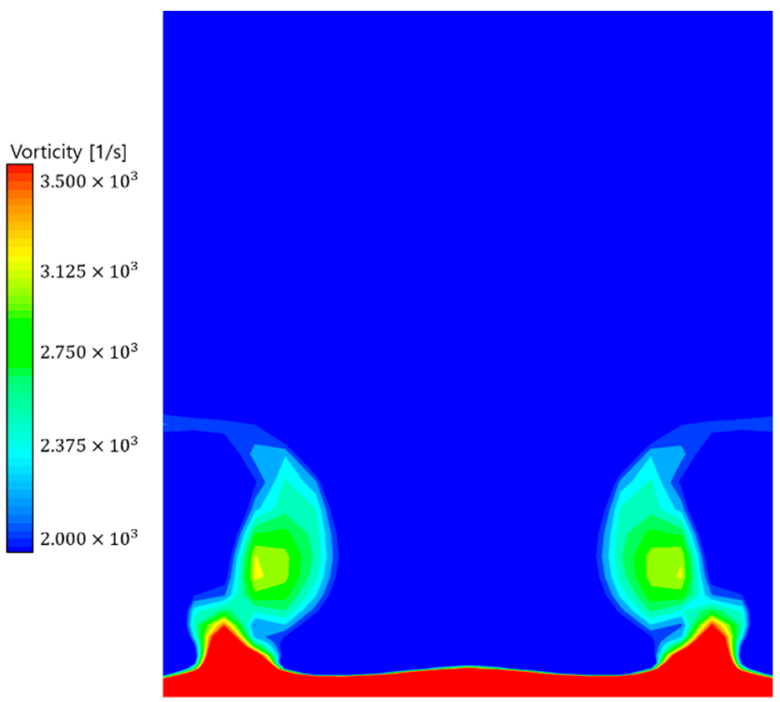

(a)

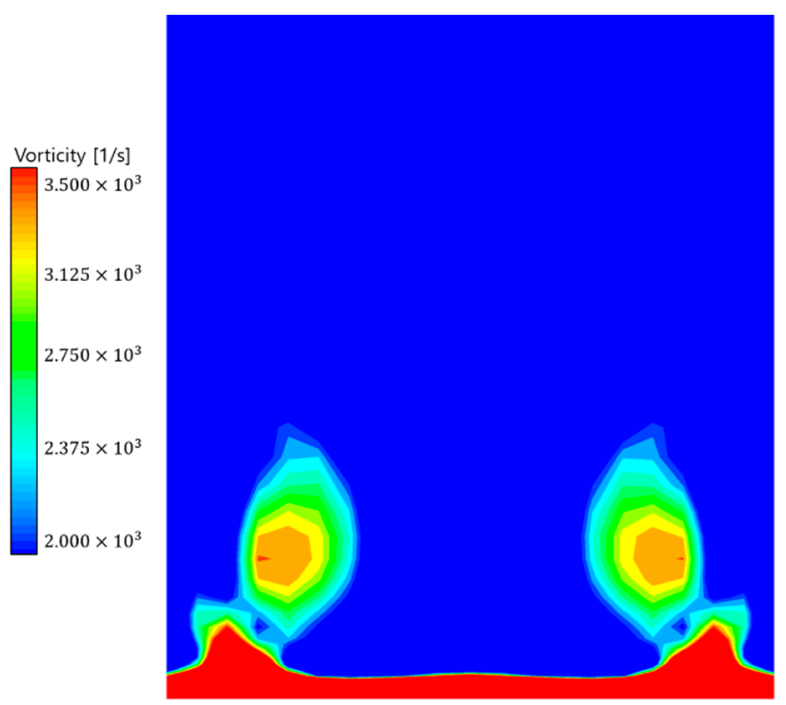

(b)

Figure 12. Cont. 


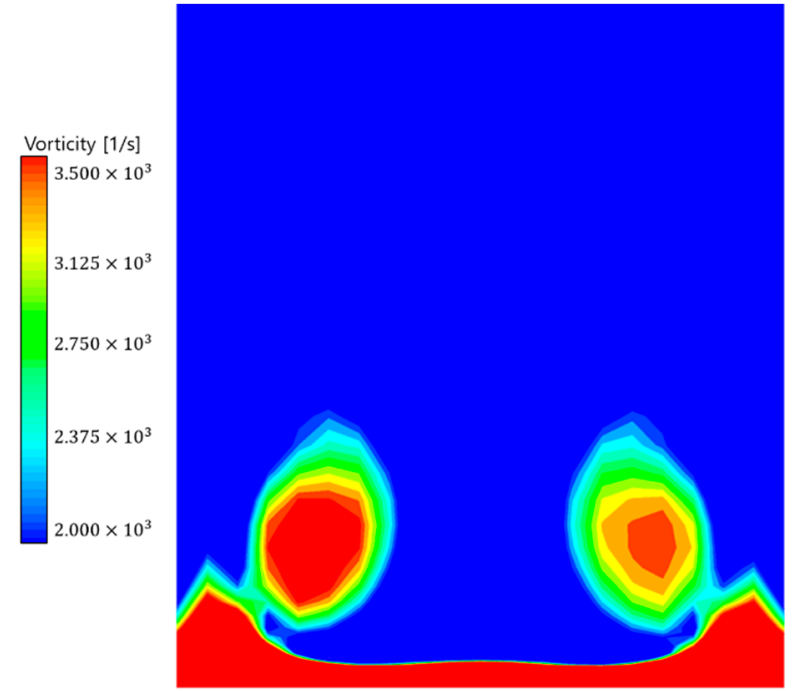

(c)

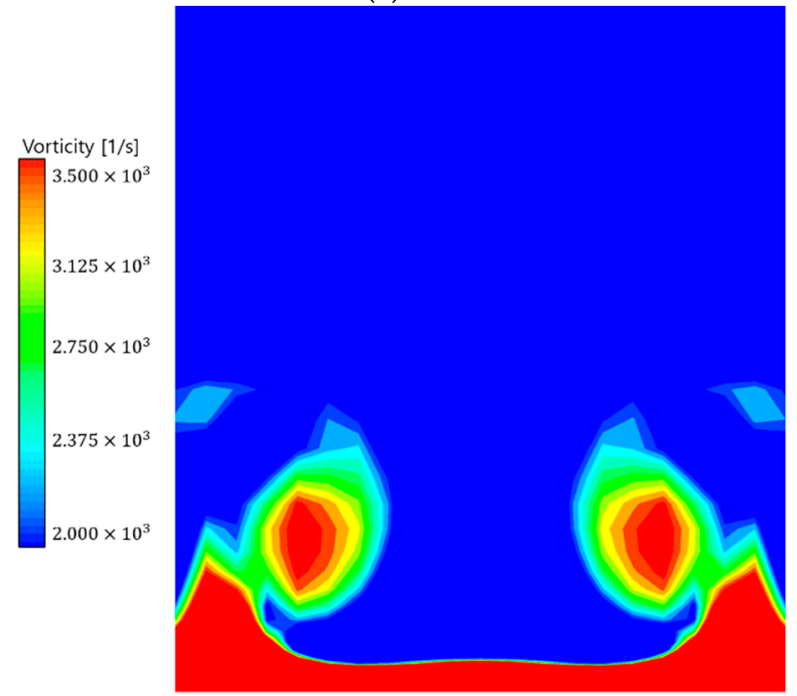

(e)

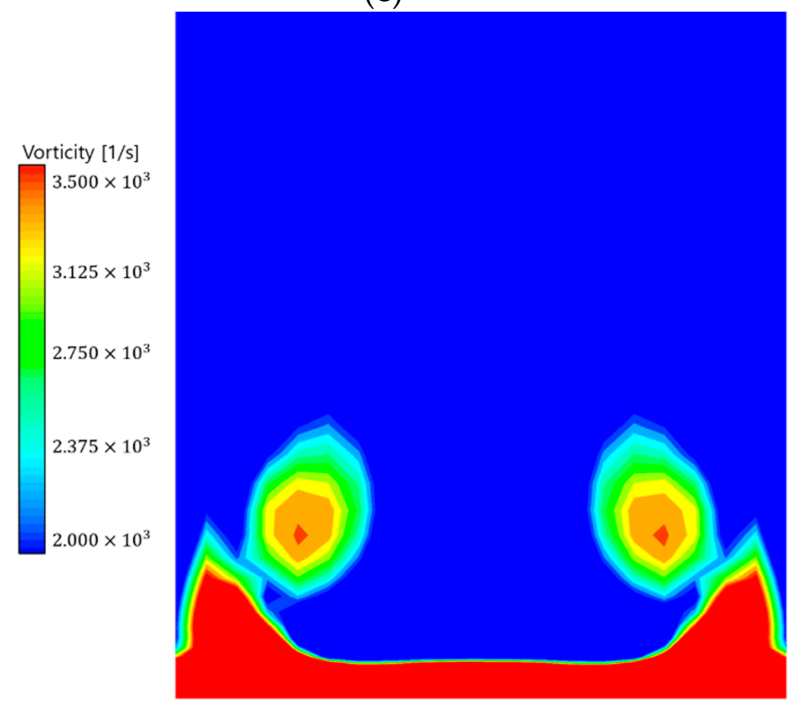

(g)

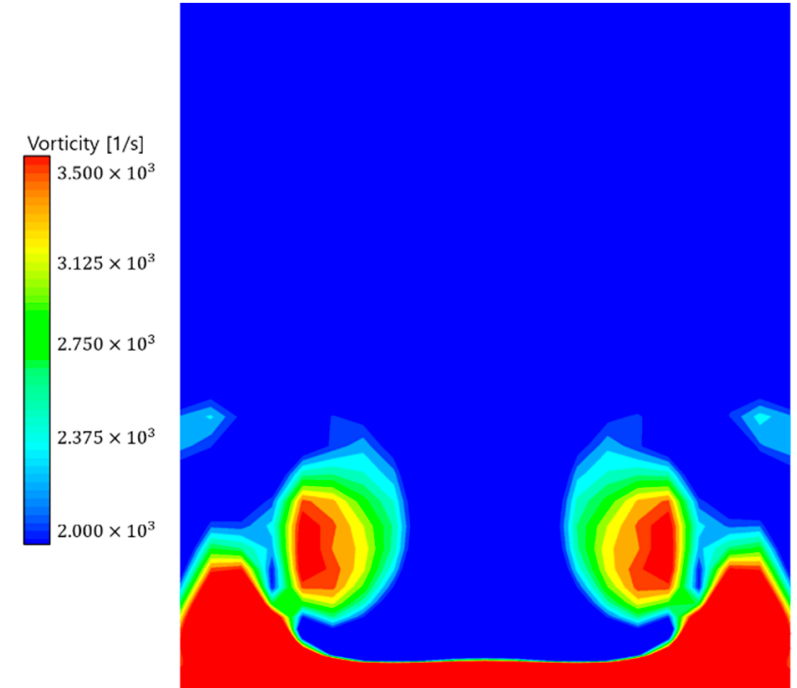

(d)

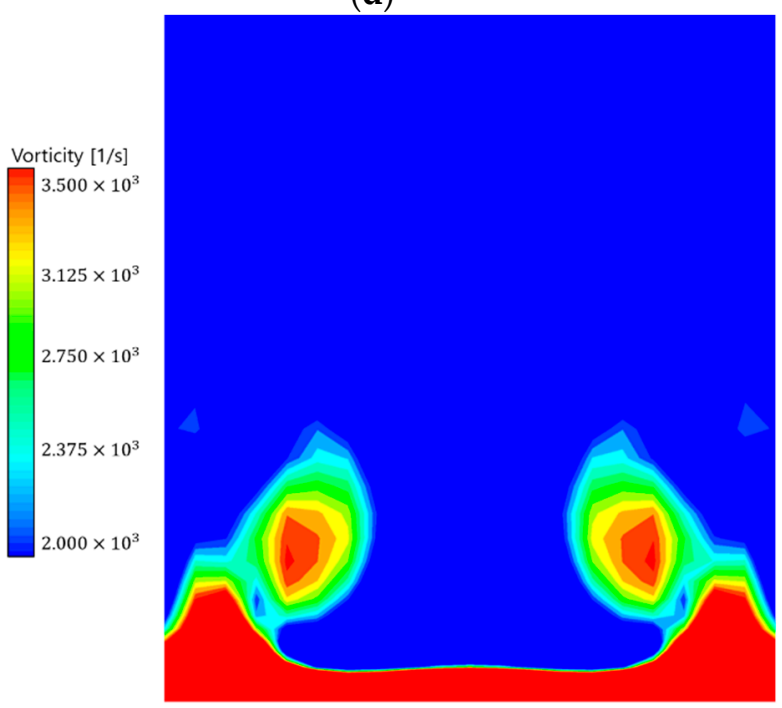

(f)

Figure 12. Vorticity contours at the midpoint of the chord: (a) Case 1; (b) Case 2; (c) Case 3; (d) Case 5; (e) Case 8; (f) Case $11 ;($ g) Case 20. 


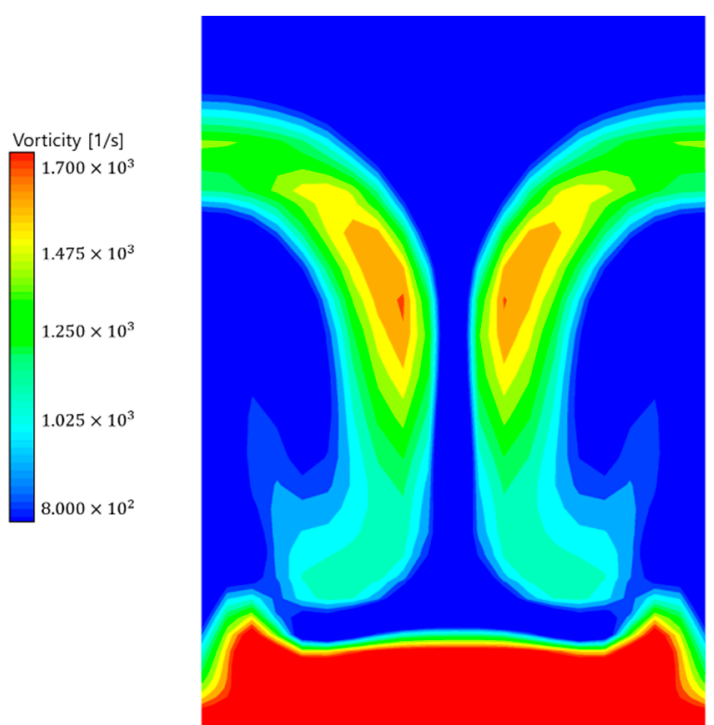

(a)

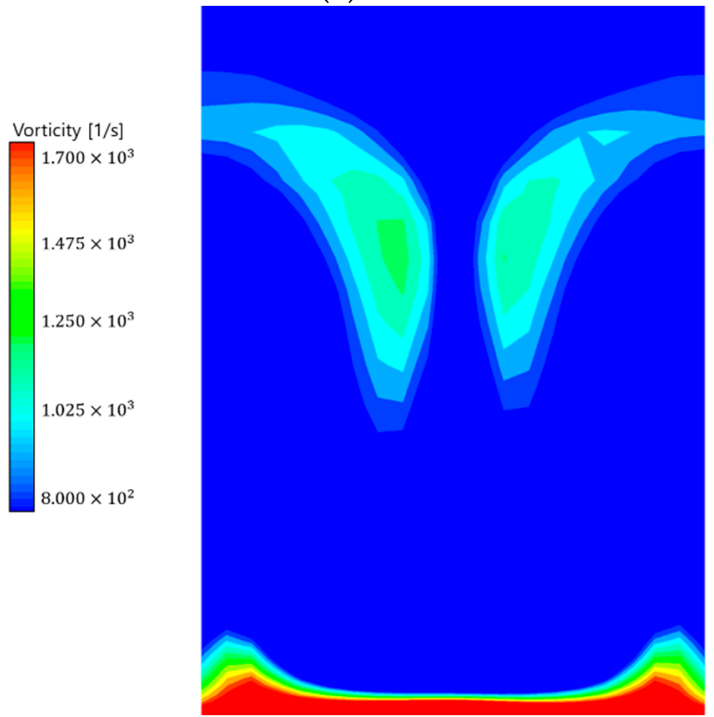

(c)

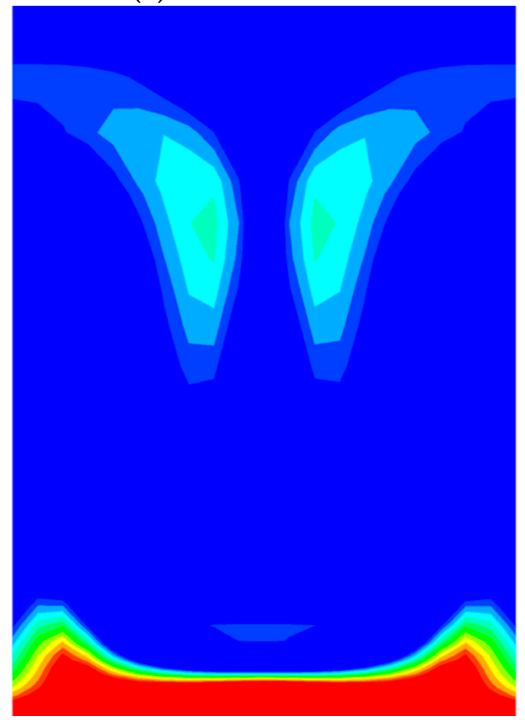

(e)

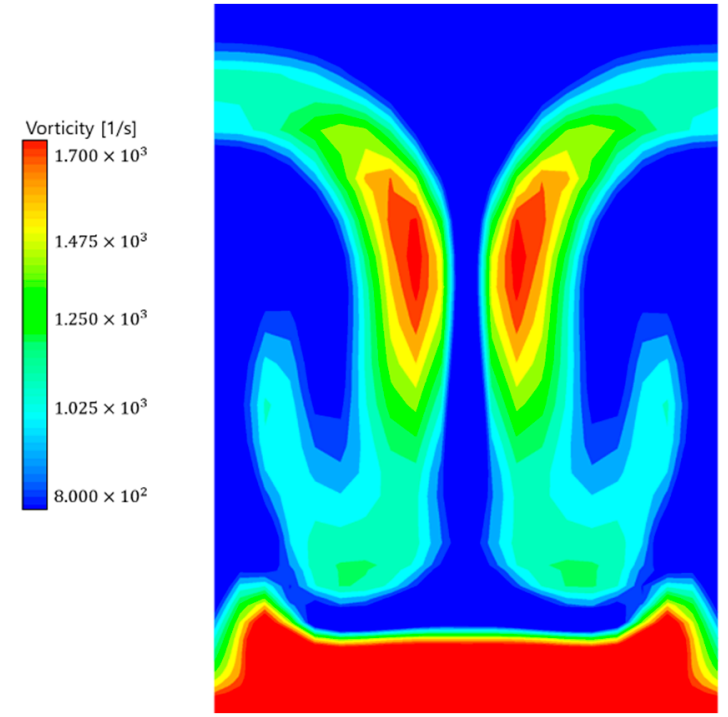

(b)

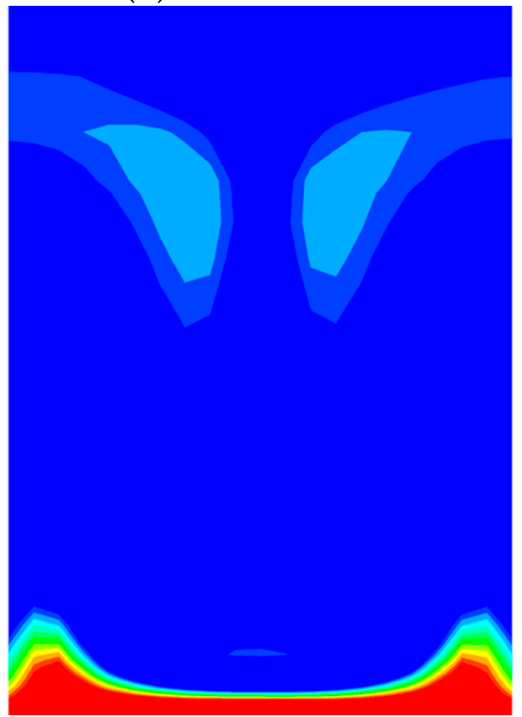

(d)

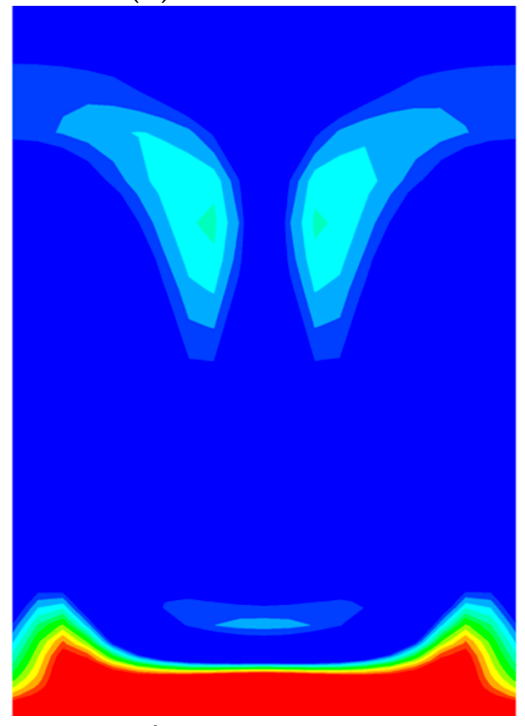

(f)

Figure 13. Cont. 


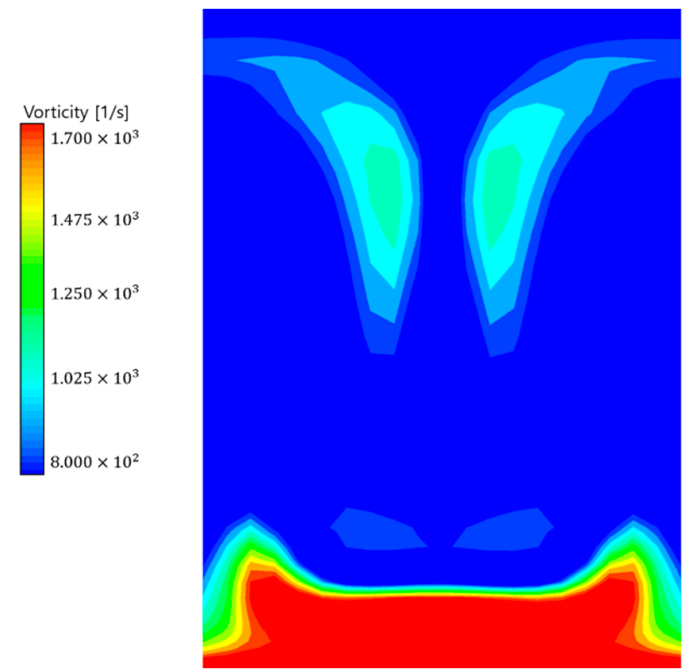

(g)

Figure 13. Vorticity contours at the trailing edge: (a) Case 1; (b) Case 2; (c) Case 3; (d) Case 5; (e) Case 8; (f) Case 11; (g) Case 20.

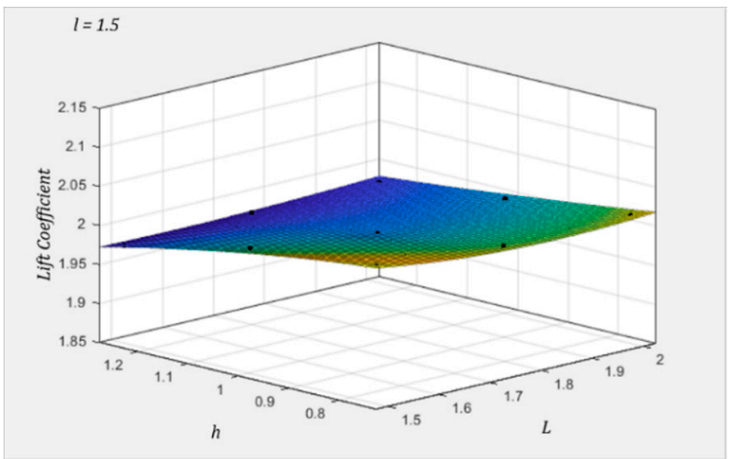

(a)

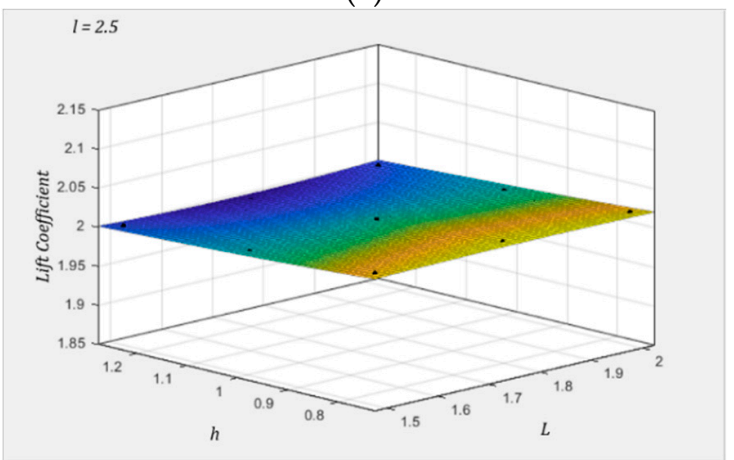

(c)

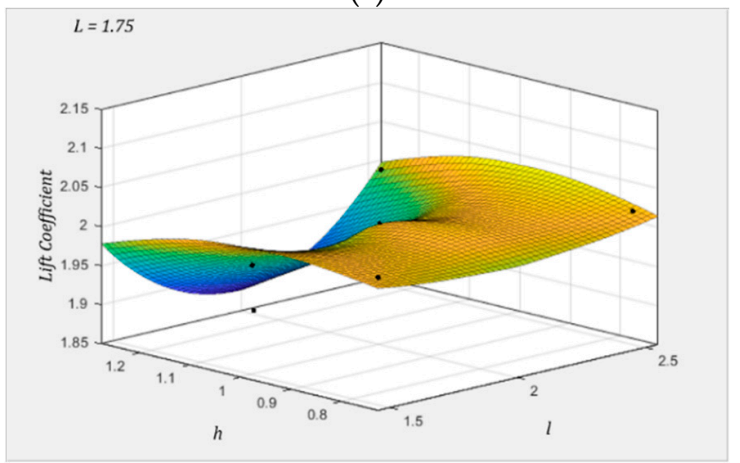

(e)

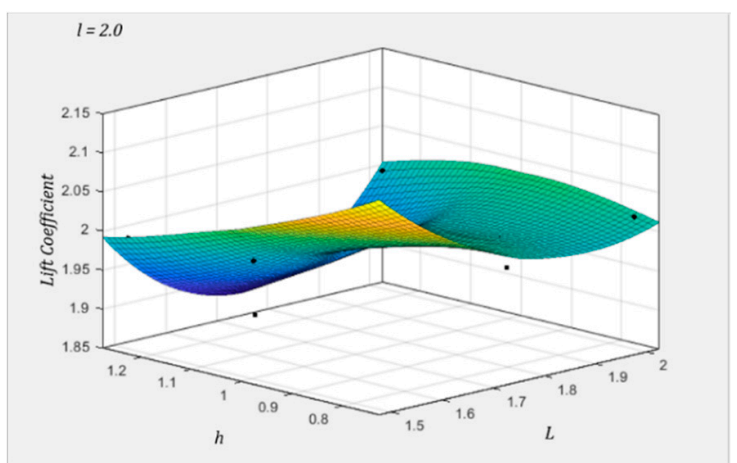

(b)

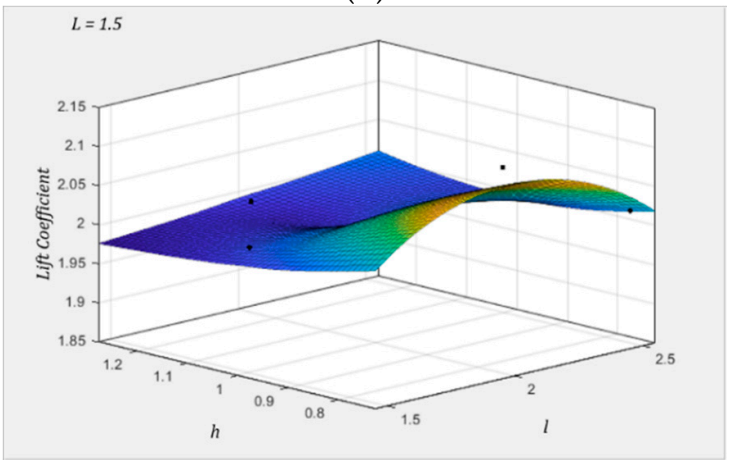

(d)

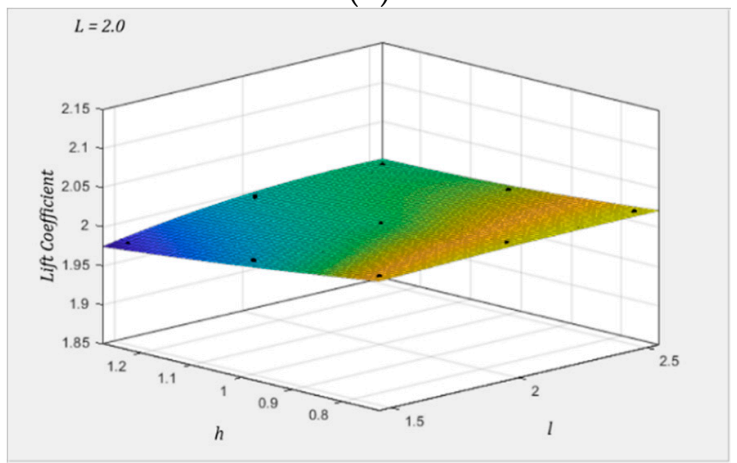

(f)

Figure 14. Cont. 


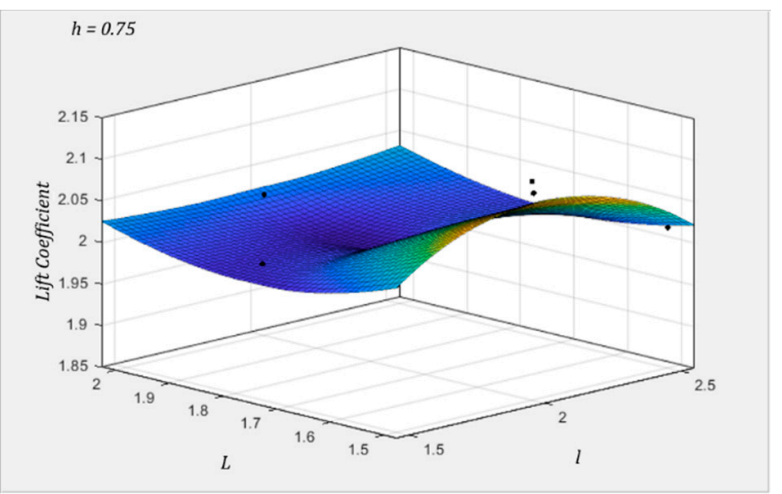

(g)

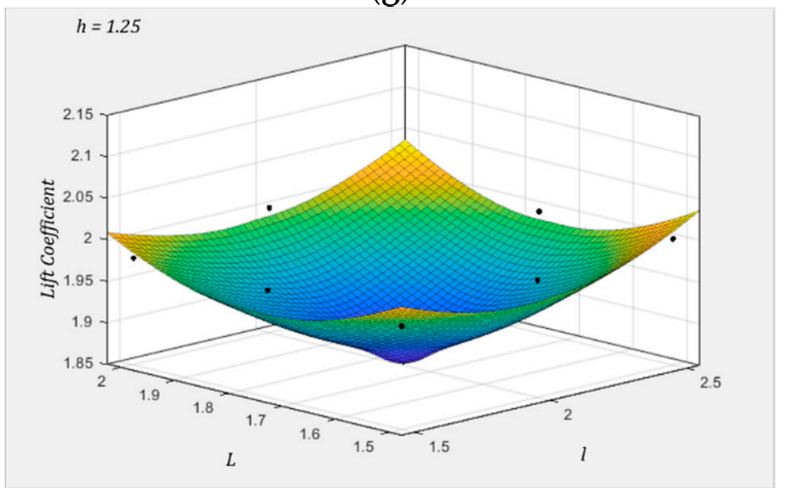

(i)

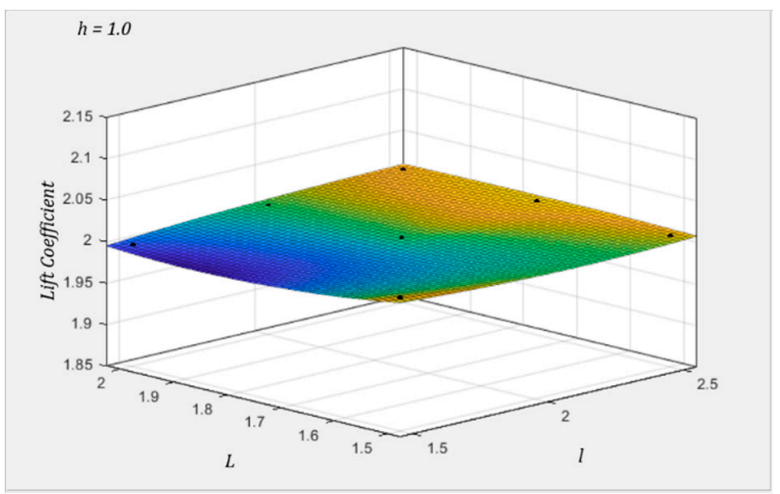

(h)

Figure 14. Surface plots of $C_{L}$ showing the effect of three parameters on the lift coefficient: (a) $l=1.5 ;(\mathbf{b}) l=2.0$; (c) $l=2.5$; (d) $L=1.5 ;(\mathbf{e}) L=1.75 ;(\mathbf{f}) L=2.0 ;($ g) $h=0.75 ;(\mathbf{h}) h=1.0 ;(\mathbf{i}) h=1.25$.

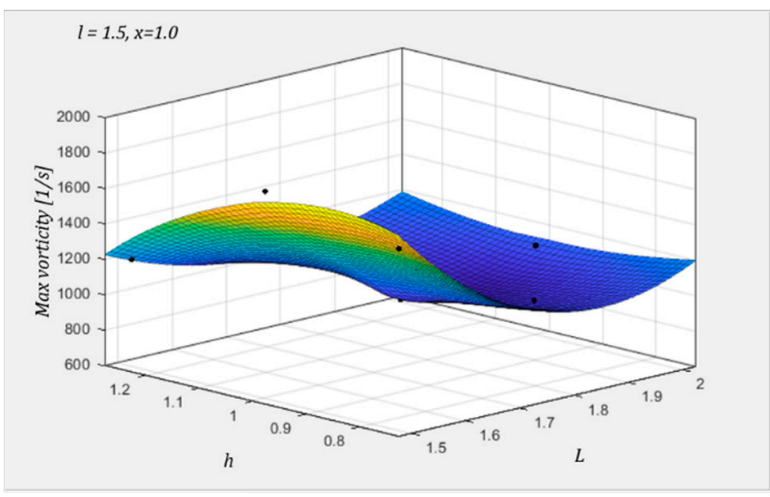

(a)

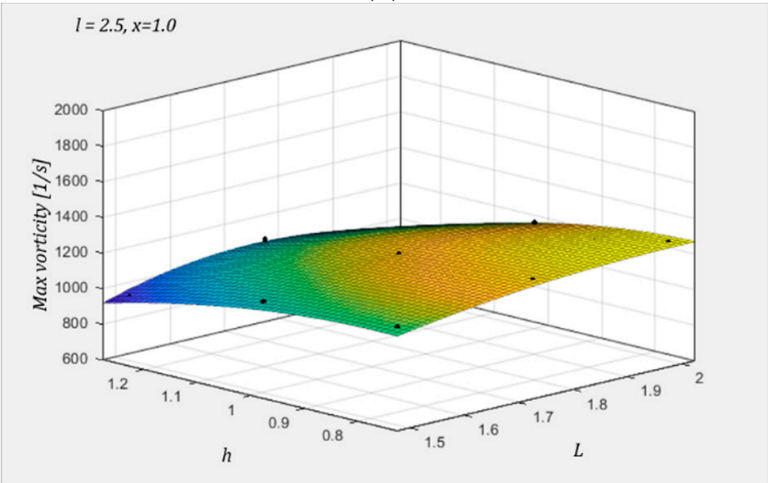

(c)

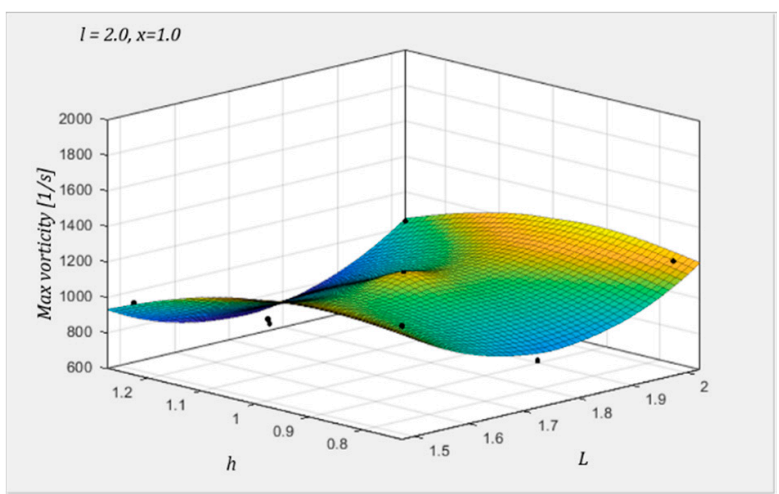

(b)

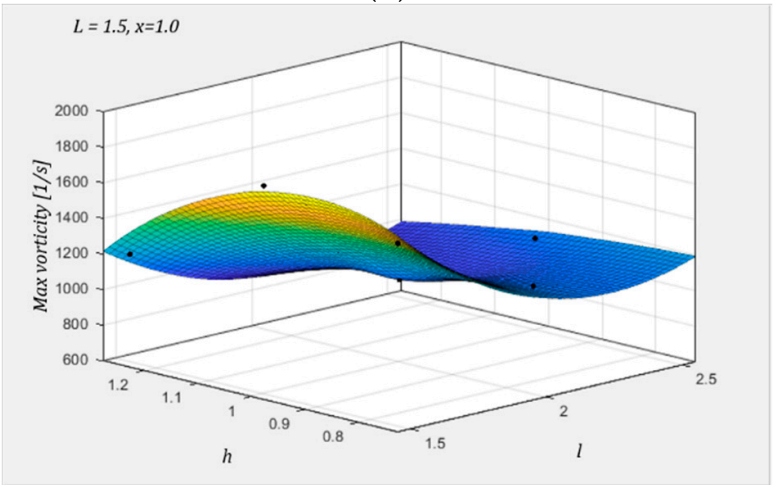

(d)

Figure 15. Cont. 


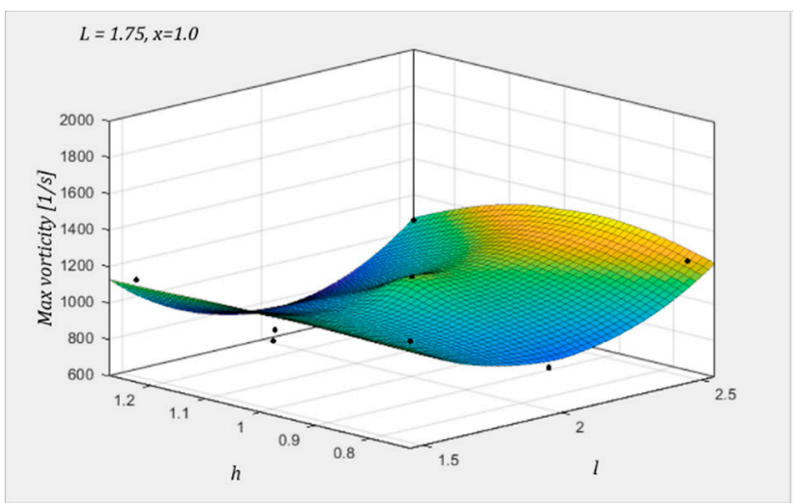

(e)

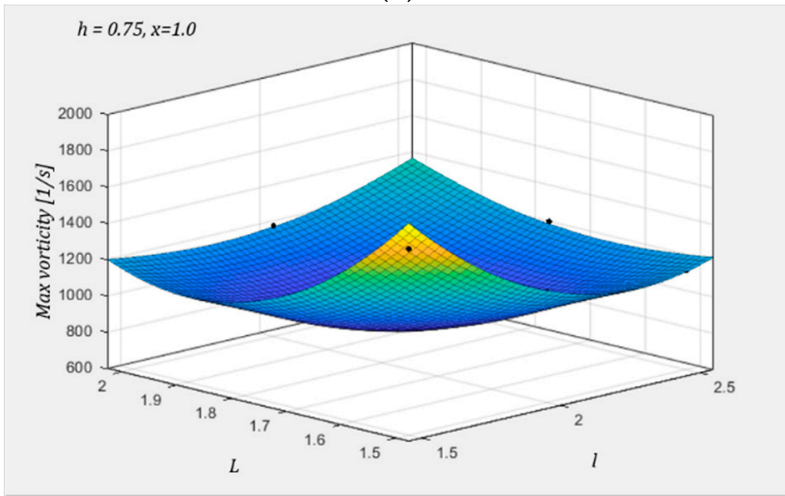

(g)

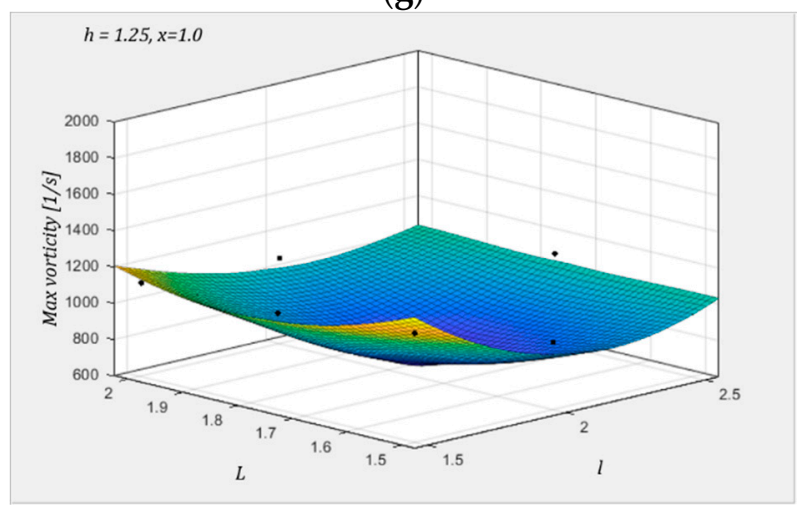

(i)

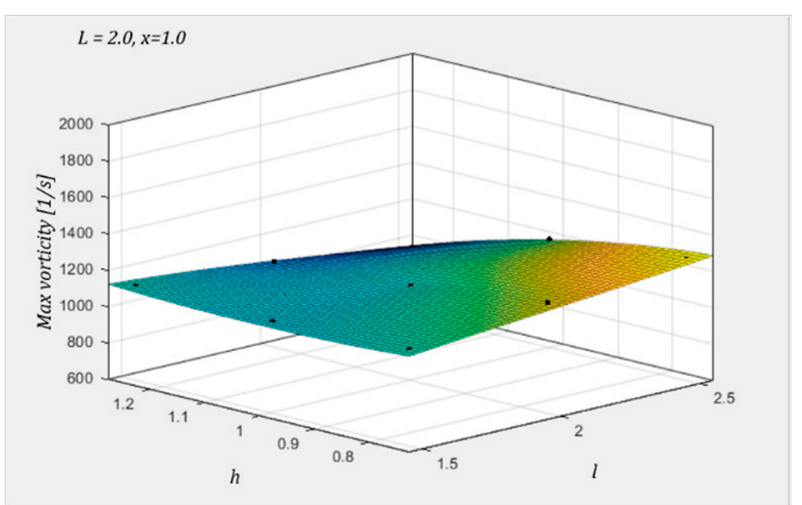

(f)

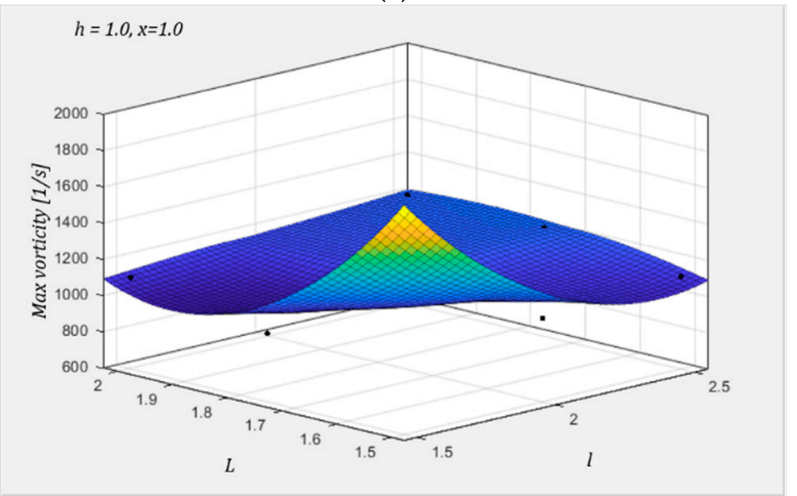

(h)

Figure 15. Surface plots showing the effect of three parameters on the maximum vorticity at the trailing edge: (a) $l=1.5$ (b) $l=2.0 ;$ (c) $l=2.5 ;$ (d) $L=1.5 ;$ (e) $L=1.75 ;$ (f) $L=2.0 ;$ (g) $h=0.75 ;$ (h) $h=1.0$; (i) $h=1.25$.

\subsection{Aerodynamic Characteristics of Wind Turbine Blade with VG}

The CFD analysis of the viscous sub-layer was precisely performed by composing the entire grid with a hexahedron. Figure 16 shows the surface grid of the VG-mounted blade used for the simulation, and the number of grids is provided in Table 8. A pair of VGs each generates a vortex in the opposite direction and a high-energy fluid flows into the boundary layer region of the low-energy flow field. Figure 17 shows the characteristics of the fluid flow and the CFD results of the structural analysis of the vortex created by the VG. The analysis confirmed that a tip vortex was generated at the tip of the VG and a horseshoe-shaped vortex formed at the lower front of the VG. Figure 18a,b shows that the flow separation is relatively reduced on the suction side compared to the baseline blade. Figure 19a,b shows that the VG forms a vortex and pushes the separation fluid to a distance of $8 \mathrm{~m}$ from the root, where flow separation is dominant. The shaft power 
was calculated by multiplying the torque and angular velocity of the simulation results. The calculated shaft power without and with the VG-mounted blade was $2365 \mathrm{~kW}$ and $2433 \mathrm{~kW}$, respectively, confirming a $2.80 \%$ increase in the shaft power compared with the result before installation.

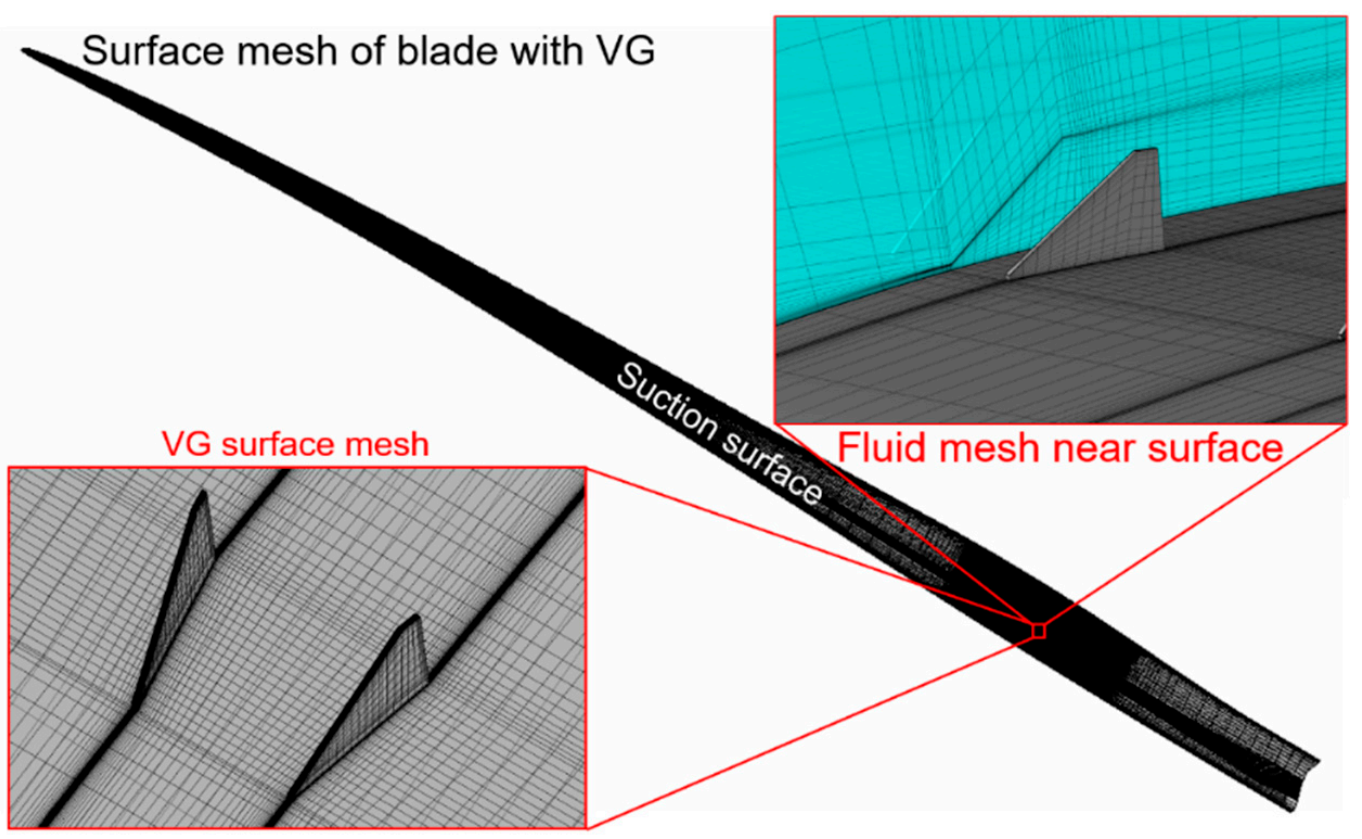

Figure 16. Surface mesh of VG-mounted blade.

Table 8. Number of elements of VG-mounted blade for numerical analysis.

\begin{tabular}{ccc}
\hline Simulation Region & Volume & No. of Elements \\
\hline & VG & $4,397,440$ \\
VG Blade & Rotatory & $49,693,662$ \\
& Stationary & $1,584,000$ \\
& Total & $55,675,102$ \\
\hline
\end{tabular}

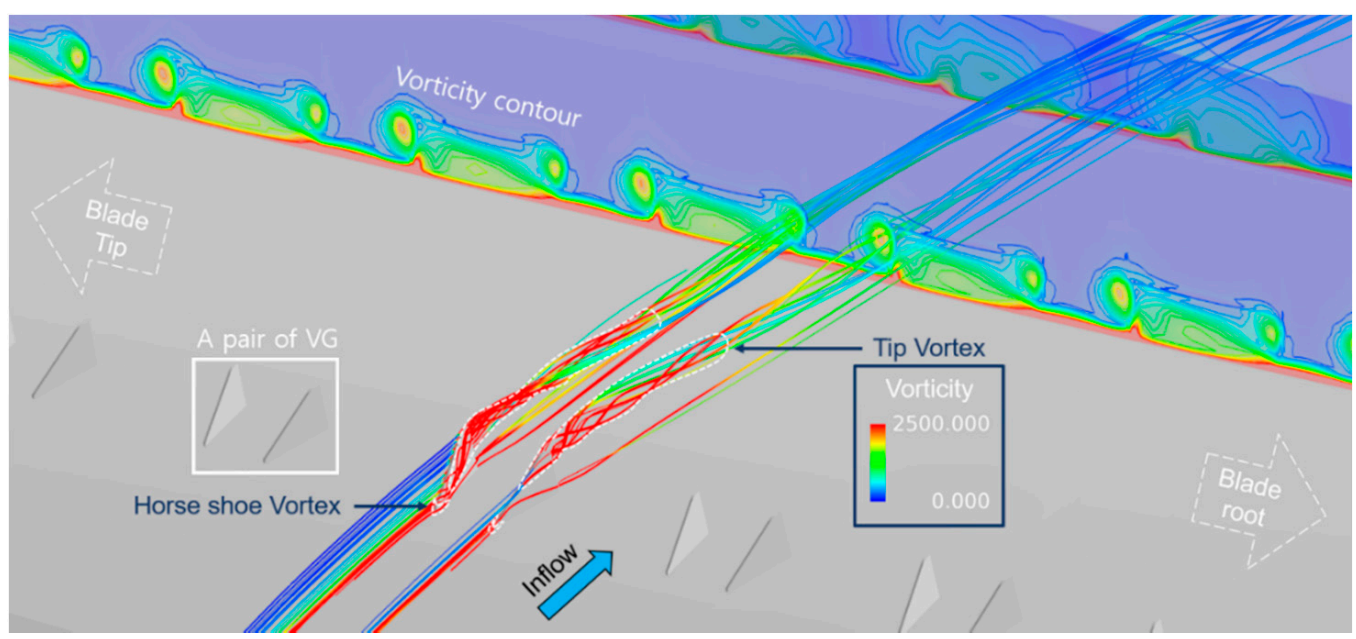

Figure 17. Flow characteristics near VG and vortex formed by VG. 


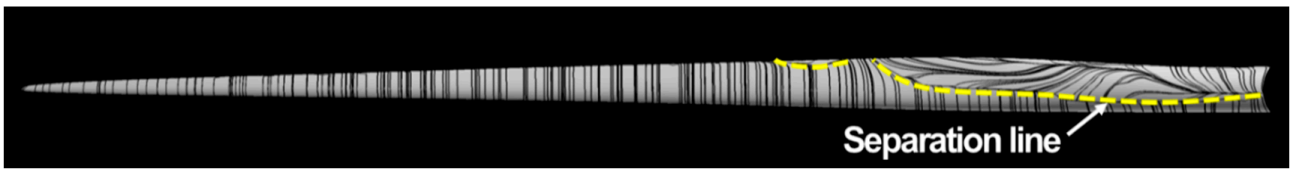

(a)

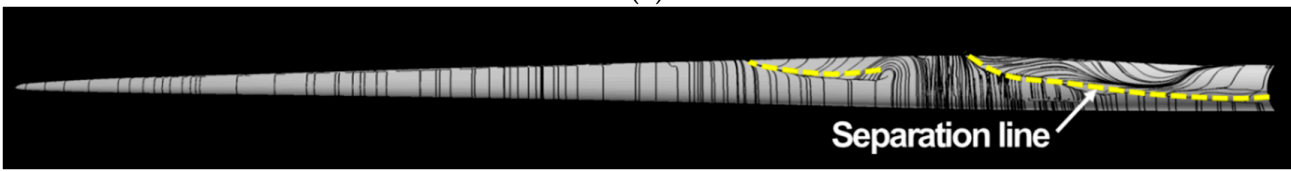

(b)

Figure 18. Surface streamline of wind turbine blade (a) without and (b) with the VGs.

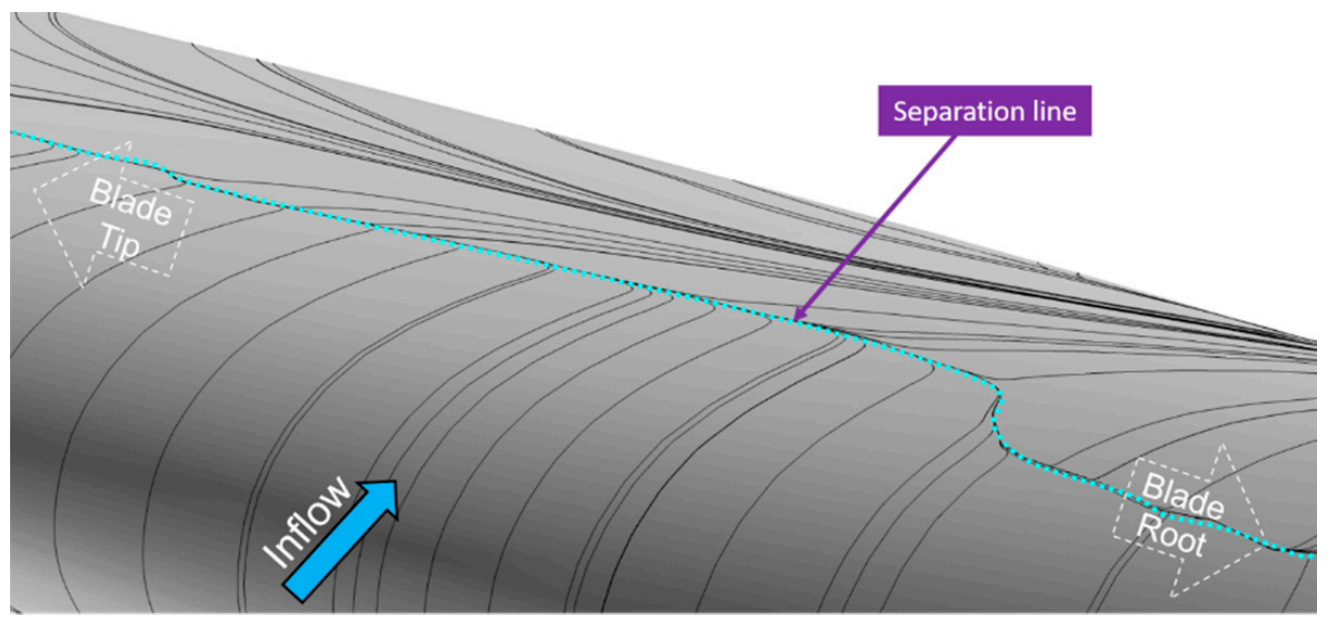

(a)

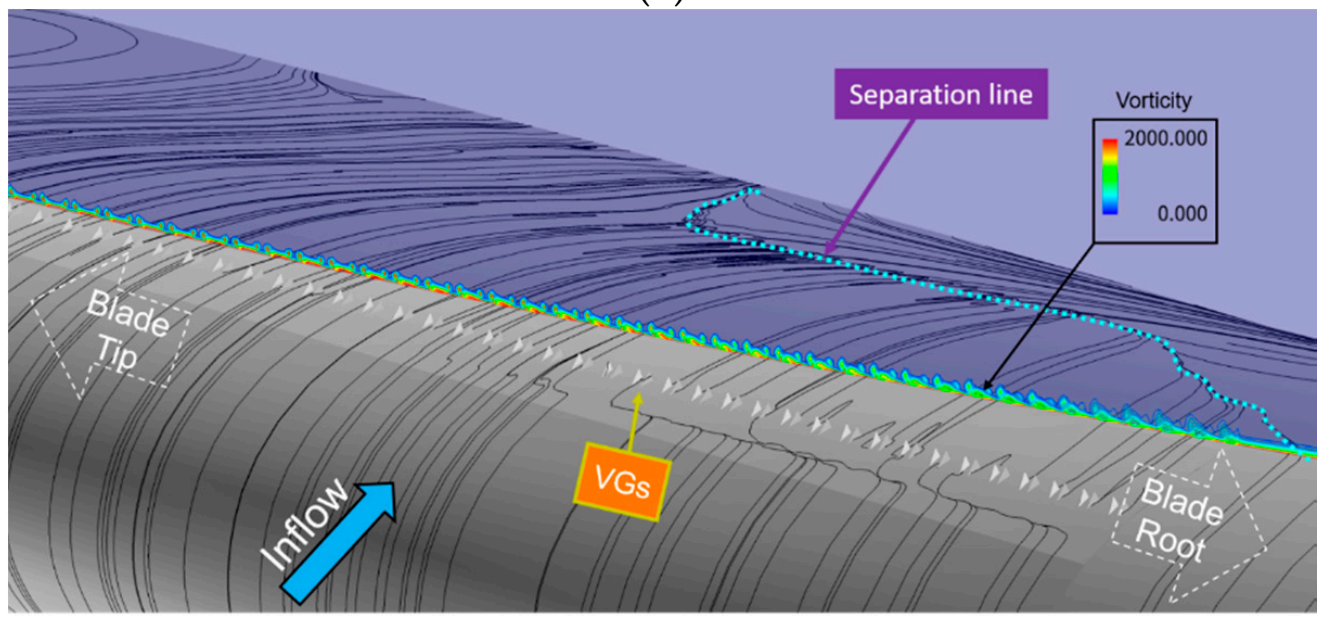

(b)

Figure 19. Separation line and surface streamline of blade (a) without VG and (b) with VGs.

\section{Conclusions}

In this study, a CFD-based in-depth investigation was conducted to determine the effects of the shape of the VG and the layout of VGs on the power performance of a wind turbine. The RSM was used to investigate the influence of VG design variables, and complex simulations using more than 55 million elements were carried out. Based on the in-depth investigation, the following conclusions were drawn.

1. A CFD analysis of multi-MW wind turbine blades was performed, and subsequently validated by comparing the results with those obtained with the GH Bladed design values. 
2. The influence of the VG design parameters was investigated using CFD analysis, which confirmed that the VG reduced the occurrence of separation flow, increased the lift, and reduced the drag at high angles of attack.

3. Analysis of the flow characteristics of the blade with the mounted VGs confirmed that the tip vortex generated by the VG reduced the separation area by allowing the high-energy fluid to flow to the low-energy separation area.

4. The VGs were confirmed to play an important role by improving the aerodynamics of multi-MW wind turbines by $2.80 \%$ at the rated wind speed. This was confirmed by the simulation at the rated wind speed with more than 55 million elements.

5. The results of this study are expected to be useful for selecting the mounting position and shape of the VG by conducting a full-scale simulation by automating the construction of the simulation environment.

The selected VG discussed in this study is currently installed in a 2.3 MW wind turbine and is being monitored using SCADA systems. The VG could also be installed on other large wind turbines by using the proposed method for constructing a computational environment.

Author Contributions: Conceptualization, J.-H.J. and K.H.; methodology, J.-H.J.; software, H.-G.M.; validation, J.-H.J. and H.-G.M.; formal analysis, J.-H.J. and H.-G.M.; investigation, H.-G.M. and J.-H.J.; resources, S.P.; data curation, S.P.; writing—original draft preparation, H.-G.M.; writing-review and editing, H.-G.M.; visualization, H.-G.M.; supervision, J.-H.J. and K.H.; project administration, J.-H.J.; funding acquisition, J.-H.J. All authors have read and agreed to the published version of the manuscript.

Funding: This work was supported by Korea Institute of Energy Technology Evaluation and Planning (KETEP) grant funded by the Korea government (MOTIE) (20203020020030, Feasibility Study of 20 MW Super-Capacity Wind Turbine Generator System Development).

Institutional Review Board Statement: Not applicable.

Informed Consent Statement: Not applicable.

Acknowledgments: This work was partly supported by a Korea Institute of Energy Technology Evaluation and Planning (KETEP) grant funded by the Korean government (MOTIE) (20203020020030, Feasibility Study of 20 MW Super-Capacity Wind Turbine Generator System Development).

Conflicts of Interest: The authors declare no conflict of interest.

\section{References}

1. Kuroiwa, T.; Karikomi, K.; Hayashi, Y.; Shibata, M.; Ueda, Y. New products and technologies of Mitsubishi wind turbines. Tech. Rev. 2004, 41, 1-5.

2. Paliszewski, D. SWT-3.0-101 an Example of Systems Engineering. In Proceedings of the NREL Wind Energy Systems Engineering Workshop, Boulder, CO, USA, 14 December 2010.

3. Grasso, F. Development of Thick Airfoils for Wind Turbines. In Proceedings of the 50th AIAA Aerospace Sciences Meeting, Nashville, TN, USA, 9-12 January 2012; p. AIAA2012-0236.

4. Berg, D.E. Aerodynamic and aeroacoustic properties of flatback airfoils. In Proceedings of the Meeting and Exhibit 27th ASME Wind Energy Symposium, Orlando, FL, USA, 5-8 January 2009.

5. Kim, S.H.; Kim, C.G. Optimal Design of Composite Stiffened Panel with Cohesive Elements using Micro-Genetic Algorithm. J. Compos. Mater. 2008, 42, 2259-2273. [CrossRef]

6. Yoshinori, U. Development of Next Generation 2 MW Class Large Wind Turbines. Mitsubishi Heavy Ind. Tech. Rev. 2004, 41, 1-4.

7. Eggleston, D.M.; Stoddard, F.S. Wind Turbine Engineering Design; Van Nostrand Reinhoid: New York, NY, USA, 1987.

8. Manwell, J.F.; McGowan, J.G.; Rogers, A.L. Wind Energy Explained; John Wiley \& Sons Ltd.: New York, NY, USA, 2002.

9. Kishinami, K.; Taniguchi, H.; Suzuki, J.; Ibano, H.; Kazunou, T.; Turuhami, M. Theoretical and experimental study on the aerodynamic characteristics of a horizontal axis wind turbine. Energy 2005, 30, 2089-2100. [CrossRef]

10. Fuglsang, P.; Bak, C.; Schepers, J.G.; Bulder, B.; Cockerill, T.T.; Claiden, P.; Olesen, A.; Van Rossen, R. Site specific design optimization of wind turbines of 1.5-2.0 MW wind turbines. Wind Energy 2002, 5, 261-279. [CrossRef]

11. Burton, T.; Sharpe, D.; Jenkins, N.; Bossanyi, E. Wind Energy Handbook, Wind Energy; Wiley: Chichester, UK, 2001.

12. Hansen, M.O.L.; Johansen, J. Tip Studies Using CFD and Comparison with Tip Loss Models. Wind Energy 2004, 7, 343-356. [CrossRef]

13. Martinez, J.; Bernabini, L.; Probst, O.; Rodriguez, C. An Improved BEM Model for the Power Curve Prediction of Stall-regulated Wind Turbines. Wind Energy 2005, 8, 385-402. [CrossRef] 
14. Jeong, J.; Yoo, C.; Lee, J.; Kim, K.H.; Choi, J.-W. 3-Dimensional Flow Field Analysis and Tip Shape Design in a 2.5 MW Wind Turbine Blade. In Proceedings of the Korea Wind Energy Association, Spring Conference, Daegu, Korea, 7-8 April 2011; pp. 51-56.

15. Jeong, J.; Yoo, C.; Lee, J.; Kim, K.H.; Choi, J.-W. 3-Dimensional Flow Field Analysis and Tip Shape Design in a Wind Turbine Blade. In Proceedings of the Korean Society for Computational Fluids Engineering, Spring Conference, Jeju, Korea, 26 May 2011; pp. 243-248.

16. Velte, C.M.; Hansen, M.O.L.; Meyer, K.E.; Fuglsang, P. Evaluation of the performance of vortex generators on the DU 91-W2-250 profile using stereoscopic PIV. In Proceedings of the 12th World Multi-Conference on Systemics, Cybernetics and Informatics (WMSCI 2008), Orlando, FL, USA, 29 June-2 July 2007; pp. 263-267.

17. Hansen, M.O.L.; Velte, C.M.; Øye, S.; Hansen, R.; Sørensen, N.N.; Madsen, J.; Mikkelsen, R. Aerodynamically shaped vortex generators. Wind Energy 2016, 19, 563-567. [CrossRef]

18. Kusunose, K.; Yu, N.J. Vortex Generator Installation Drag on an Airplane Near Its Cruise Condition. J. Aircr. 2003, 40, 1145. [CrossRef]

19. Khoshvaght-Aliabadi, M.; Zangouei, S.; Hormozi, F. Performance of a plate-fin heat exchanger with vortex-generator channels: 3D-CFD simulation and experimental validation. Int. J. Therm. Sci. 2015, 88, 180-192. [CrossRef]

20. Astolfi, D.; Castellani, F.; Fravolini, M.L.; Cascianelli, S.; Terzi, L. Precision computation of wind turbine power upgrades: An aerodynamic and control optimization test case. J. Energy Resour. Technol. 2019, 141, 051205. [CrossRef]

21. Hwangbo, H.; Ding, Y.; Eisele, O.; Weinzierl, G.; Lang, U.; Pechlivanoglou, G. Quantifying the effect of vortex generator installation on wind power production: An academia-industry case study. Renew. Energy 2017, 113, 1589-1597. [CrossRef]

22. Sørensen, N.N.; Zahle, F.; Bak, C.; Vronsky, T. Prediction of the Effect of Vortex Generators on Airfoil Performance. J. Phys. 2014, 524, 012019. [CrossRef]

23. Øye, S. The effect of vortex generators on the performance of the ELKRAFT $1000 \mathrm{KW}$ turbine. In Proceedings of the Aerodynamics of Wind Turbines: 9th IEA Symposium, Stockholm, Sweden, 11-12 December 1995; pp. 9-14.

24. Mueller-Vahl, H.; Pechlivanoglou, G.; Nayeri, C.; Paschereit, C. Vortex generators for wind turbine blades: A combined wind tunnel and wind turbine parametric study. In Proceedings of the ASME Turbo Expo 2015: Turbine Technical Conference and Exposition, Copenhagen, Denmark, 11-15 June 2012; pp. 899-914.

25. Troldborg, N.; Zahle, F.; Sørensen, N.N. Simulations of wind turbine rotor with vortex generators. J. Phys. Conf. Ser. 2016, 753, 022057. [CrossRef]

26. Aramendia, I.; Fernandez-Gamiz, U.; Ramos-Hernanz, J.A.; Sancho, J.; Lopez-Guede, J.M.; Zulueta, E. Flow control devices for wind turbines. In Energy Harvesting and Energy Efficiency; Springer: Cham, Switzerland, 2017; pp. 629-655.

27. Chillon, S.; Uriarte-Uriarte, A.; Aramendia, I.; Martínez-Filgueira, P.; Fernandez-Gamiz, U.; Ibarra-Udaeta, I. jBAY modeling of vane-type vortex generators and study on airfoil aerodynamic performance. Energies 2020, 13, 2423. [CrossRef]

28. Wu, Z.; Chen, T.; Wang, H.; Shi, H.; Li, M. Investigate aerodynamic performance of wind turbine blades with vortex generators at the transition area. Wind Eng. 2021, 1-15, 0309524X211038542. [CrossRef]

29. Fernandez-Gamiz, U.; Zulueta, E.; Boyano, A.; Ansoategui, I.; Uriarte, I. Five megawatt wind turbine power output improvements by passive flow control devices. Energies 2017, 10, 742. [CrossRef]

30. ANSYS Inc. ANSYS CFX-Solver Theory Guide. Release 12.1. 2009. Available online: www.ansys.com (accessed on 14 November 2021).

31. Harrad Hassan, G.; Partners Ltd. Bladed Theory Manual Version 4.3. 2012. Available online: www.gl-harradhassan.com (accessed on 14 November 2021).

32. Li, X.K.; Liu, W.; Zhang, T.J.; Wang, P.M.; Wang, X.D. Analysis of the effect of vortex generator spacing on boundary layer flow separation control. Appl. Sci. 2019, 9, 5495. [CrossRef]

33. Orszagt, S.A. Analytical theories of turbulence. J. Fluid Mech. 1970, 41, 363-386. [CrossRef]

34. Smagorinsky, J. General circulation experiments with the primitive equations, i. the basic experiment. Mon. Weather. Rev. 1963, 91, 99-164. [CrossRef]

35. Brdina, J.E.; Huang, P.G.; Coakley, T.J. Turbulence modeling validation, testing and development. NASA Tech. Memo. 1997, $110446,147$.

36. Wilcos, D.C. Re-assessment of the scale-determining equation for advanced turbulence models. AIAA J. 1988, 26, 1299-1310. [CrossRef]

37. Menter, F.R. Two-equation eddy-viscosity turbulence models for engineering applications. AIAA J. 1994, 32, 1598-1605. [CrossRef]

38. Andre, F.P.R.; Armando, M.A.; Herbert, M.G. An airfoil optimization technique for wind turbines. In Proceedings of the 21st Brazilian Congress of Mechanical Engineering, Natal, Brazil, 24-28 October 2011.

39. Chen, X.M.; Agarwal, R. Optimization of flatback airfoils for wind-turbine blades using a genetic algorithm. J. Aircr. 2012, 49, 622-629. [CrossRef]

40. Langtry, R.B.; Menter, F.R. Transition Modeling for General CFD Applications in Aeronautics. AIAA J. 2005, 522. [CrossRef]

41. Cleveland, W.S. Robust locally weighted regression and smoothing scatterplots. J. Am. Stat. Assoc. 1979, 74, 829-836. [CrossRef] 